\title{
Frequent downregulation of $L R R C 26$ by epigenetic alterations is involved in the malignant progression of triple-negative breast cancer
}

\author{
YOSHIMASA MIYAGAWA $^{1,2^{*}}$, YOSUKE MATSUSHITA ${ }^{1 *}$, HIROMU SUZUKI $^{3}$, MASATO KOMATSU $^{1}$, \\ TETSURO YOSHIMARU ${ }^{1}$, RYUICHIRO KIMURA ${ }^{1}$, AYAKO YANAI ${ }^{1,2}$, JUNKO HONDA $^{4}$, AKIRA TANGOKU $^{5}$, \\ MITSUNORI SASA $^{6}$, YASUO MIYOSHI ${ }^{2}$ and TOYOMASA KATAGIRI ${ }^{1}$ \\ ${ }^{1}$ Division of Genome Medicine, Institute for Genome Research, Tokushima University, Tokushima 770-8503; \\ ${ }^{2}$ Department of Surgery, Division of Breast and Endocrine Surgery, Hyogo College of Medicine, \\ Nishinomiya, Hyogo 663-8501; ${ }^{3}$ Department of Molecular Biology, Sapporo Medical University, Sapporo, \\ Hokkaido 060-8556; ${ }^{4}$ Department of Surgery, National Hospital Organization Higashitokushima Medical Center, \\ Tokushima 779-0193; ${ }^{5}$ Department of Thoracic and Endocrine Surgery and Oncology, Institute of Health Biosciences, \\ The University of Tokushima Graduate School, Tokushima 770-8503; ${ }^{6}$ Department of Surgery, \\ Tokushima Breast Care Clinic, Tokushima 770-0052, Japan
}

Received September 13, 2017; Accepted February 21, 2018

DOI: $10.3892 /$ ijo.2018.4301

\begin{abstract}
Triple-negative breast cancer (TNBC), defined as breast cancer lacking estrogen- and progesterone-receptor expression and human epidermal growth factor receptor 2 (HER2) amplification, is a heterogeneous disease. RNA-sequencing analysis of 15 TNBC specimens and The Cancer Genome Atlas-TNBC dataset analysis identified the frequent downregulation of leucine-rich repeatcontaining 26 (LRRC26), which negatively regulates nuclear factor- $\kappa \mathrm{B}(\mathrm{NF}-\kappa \mathrm{B})$ signaling, in TNBC tissues. Quantitative polymerase chain reaction and bisulfite pyrosequencing analyses revealed that $L R R C 26$ was frequently silenced in TNBC tissues and cell lines as a result of promoter methylation. LRRC26 expression was restored by 5-aza-2'-deoxycytidine (5'-aza-dC) treatment in HCC1937 TNBC cells, which lack LRRC26 expression. Notably, small interfering RNA-mediated knockdown of LRRC26 expression significantly enhanced the anchorage-independent growth, invasion and migration of $\mathrm{HCC} 70$ cells, whereas ectopic overexpression of LRRC26 in BT20 cells suppressed their invasion and migration. Conversely, neither knockdown nor overexpression of $L R R C 26$ had an effect on cell viability in the
\end{abstract}

Correspondence to: Dr Toyomasa Katagiri, Division of Genome Medicine, Institute for Genome Research, Tokushima University, 3-18-15 Kuramoto-cho, Tokushima 770-8503, Japan

E-mail: tkatagi@genome.tokushima-u.ac.jp

${ }^{*}$ Contributed equally

Key words: LRRC26, triple-negative breast cancer, tumor suppressor, hypermethylation absence of tumor necrosis factor- $\alpha$ (TNF- $\alpha$ ) stimulation. Meanwhile, overexpression of $L R R C 26$ caused the reduction of TNF- $\alpha$-mediated NF- $\kappa B$ luciferase reporter activity, whereas depleting $L R R C 26$ expression resulted in the upregulation of TNF- $\alpha$-mediated NF- $\kappa B$ downstream genes [interleukin- 6 (IL-6), IL-8 and C-X-C motif chemokine ligand-1]. Taken together, these findings demonstrate that $L R R C 26$ is frequently downregulated in TNBC due to DNA methylation and that it suppresses the TNF- $\alpha$-independent anchorage-independent growth, invasion and migration of TNBC cells. Loss of $L R R C 26$ function may be a critical event in the aggressiveness of TNBC

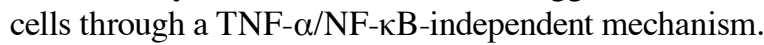

\section{Introduction}

Triple-negative breast cancer (TNBC), defined as a clinical breast cancer subtype that is negative for estrogen receptor (ER) and progesterone receptor (PgR) expression and human epidermal growth factor receptor 2 (HER2) gene amplification, accounts for $15 \%$ of all invasive breast cancer cases. TNBC comprises a heterogeneous group of tumors with different histological and molecular characteristics. Clinically, as TNBC patients do not benefit from endocrine therapies (selective estrogen receptor modulators, selective estrogen receptor downregulators and aromatase inhibitors) (1-3) or anti-HER2 drugs (trastuzumab, lapatinib, pertuzumab and trastuzumab emtansine) (4) due to a lack of targeted therapeutic receptors $(5,6)$, these therapies are not recommended in National Comprehensive Cancer Network guidelines (7). Therefore, chemotherapy using conventional cytotoxic agents, including anthracyclines, cyclophosphamides, taxanes, platinum agents and eribulin $(8,9)$, is currently the mainstay of systemic treatment, although patients with TNBC have worse outcomes following chemotherapy than patients with breast 
cancer of other subtypes, including hormone receptor-positive and HER2-positive breast cancer $(5,6,10)$. Thus, since there is no optimized standard chemotherapy protocol for TNBC, detailed subtyping of TNBC is necessary to identify more effective molecular-targeted therapies.

Current omics-based studies, such as genomics and transcriptomics, can provide data that can be used to categorize TNBC. Recent gene expression profiling-based cluster analysis using a dataset consisting of 587 TNBC cases from 21 independent datasets identified six subtypes, including two basal-like subtypes, as well as an immunomodulatory, a mesenchymal, a mesenchymal stem-like and a luminal androgen receptor subtype (11). Moreover, next generation sequencing (NGS)-based studies detected tumor protein p53 and phosphatidylinositol-4,5-bisphosphate 3-kinase catalytic subunit $\alpha$ mutations in 80 and $9 \%$ of TNBC cases, respectively (12), highlighting these gene mutations as key genetic events in this subtype. Notably, additional NGS studies led to the identification of actionable molecular characteristics, including 'BRCAness', defined as a defect in homologous recombination repair due to BRCA1 DNA repair associated (BRCA1) or BRCA2 mutation, in TNBC $(13,14)$. Recently, poly(ADP-ribose) polymerase inhibitors were shown to take advantage of synthetic lethality in targeting TNBC with BRCAness $(15,16)$. Furthermore, the nuclear factor $-\kappa B(N F-\kappa B)$ signaling pathway is constitutively activated in the basal-like subtype of breast cancer cells, $\sim 80 \%$ of which include TNBC (17). However, the underlying causes of $N F-\kappa B$ signaling activation have remained poorly understood.

To characterize the molecular features of TNBC, RNA-sequencing (RNA-seq) analysis was performed in the present study and it was found that leucine-rich repeat (LRR)-containing 26 (LRRC26), a member of the LRR superfamily, was frequently downregulated in patients with TNBC. $L R R C 26$, also known as CAPC, is reported to act as a negative regulator of $\mathrm{NF}-\kappa \mathrm{B}$ activity, and to inhibit cancer cell proliferation and migration (18). However, the pathophysiological role of $L R R C 26$ in carcinogenesis and TNBC progression, particularly the mechanisms regulating $L R R C 26$ expression, has not yet been elucidated.

The present study aimed to characterize the molecular mechanism of LRRC26 downregulation in TNBC.

\section{Materials and methods}

Cell lines and clinical specimens. The human breast cancer cell lines, MDA-MB-231, HCC1143, BT-20, BT-549, HCC1395, HCC1937, MDA-MB-157, HCC38, HCC70, MDA-MB-468, BT-474, SK-BR-3, T-47D and ZR-75-1, were purchased from the American Type Culture Collection (Rockville, MD, USA). MCF-7 cells were obtained from the Health Science Research Resources Bank (Osaka, Japan). 293T cells and MDA-MB-453 cells were provided by the RIKEN BioResource Center (Tsukuba, Japan). KPL-3C cells were kindly provided by Dr Junichi Kurebayashi (Kawasaki Medical School, Kurashiki, Okayama, Japan) (19). Each cell line was cultured according to optimal conditions recommended by their respective depositors (Table I). No Mycoplasma contamination was detected in any of the cultures using a Mycoplasma Detection kit
(Takara Bio, Inc., Otsu, Japan). A total of 26 TNBC samples and 26 normal mammary tissues were surgically resected with informed consent from patients who were treated at the Tokushima Breast Care Clinic (Tokushima, Japan), as previously described (20) (Table II). Samples were immediately embedded in TissueTek OCT compound (Sakura, Tokyo, Japan), frozen and stored at $-80^{\circ} \mathrm{C}$.

The present study, as well as the use of all clinical materials aforementioned, was approved by the Ethics Committee of Tokushima University (Tokushima, Japan).

RNA-seq analysis. Total RNA was extracted from frozen tumors and adjacent normal breast tissues from the 15 out of 26 TNBC samples that could produce a large enough amount of RNA for RNA seq analysis using the Nucleospin RNA II system (Takara Bio, Inc.) according to the manufacturer's protocols. Whole-transcriptome RNAs seq analysis was performed using the SureSelect strand-specific RNA library preparation kit (Agilent Technologies, Inc., Santa Clara, CA, USA) according to the manufacturer's protocols, followed by pairedend 100-bp sequencing on an Illumina HiSeq 1500 platform (Illumina, Inc., San Diego, CA, USA). All primary sequence data files are deposited in the DNA Data Bank of Japan (accession no. JGAS00000000116; http://www.ddbj.nig.ac.jp/). Data were analyzed using CLC Biomedical Genomics Workbench version 4.0 (Qiagen $\mathrm{GmbH}$, Hilden, Germany) with default parameters. Transcript abundance was calculated as transcript per million.

Quantitative PCR ( $P$ PCR) and semi-quantitative PCR. Total RNA extracted from clinical breast cancer samples and breast cancer cell lines using the NucleoSpin RNA II system (Takara Bio, Inc.) and the poly A-RNAs of a normal human mammary gland (Clontech Laboratories, Inc., Mountainview, CA, USA) were reverse transcribed using SuperScript II (Life Technologies; Thermo Fisher Scientific, Inc., Waltham, MA, USA). qPCR analysis using the ABI PRISM 7500 Real-Time PCR system was performed with SYBR ${ }^{\circledR}$ Premix Ex Taq (both from Applied Biosystems; Thermo Fisher Scientific, Inc.). The thermocycling conditions were $10 \mathrm{~min}$ at $94^{\circ} \mathrm{C}$, followed by 45 cycles of denaturation at $94^{\circ} \mathrm{C}$ for $15 \mathrm{sec}, 1 \mathrm{~min}$ annealing and extension at $60^{\circ} \mathrm{C}$, and reading of the fluorescence. Following threshold-dependent cycling, melting curve analysis was performed from 60 to $94^{\circ} \mathrm{C}$. The quantitative calculation was analyzed using $2^{-\Delta \Delta C q}(21)$. Semi-quantitative PCR analysis was performed as described previously $(22,23)$. Gene-specific primers used for qPCR and semi-quantitative PCR were as follows: $L R R C 26$ forward, 5'-CTGCTGCTGGACCACAACC-3' and reverse, 5'-AGAAGGCTCGCACATGCAC-3'; interleukin-6 (IL-6) forward, 5'-GGGCATTCCTTCTTCTGG-3' and reverse, 5'-ACTGCATAGCCACTTTCCA-3'; $I L-8$ forward, 5'-GCAAAATTGAGGCCAAGG-3' and reverse, 5'-GGCACA GTGGAACAAGGA-3'; and C-X-C motif chemokine ligand-1 $(C X C L-1)$ forward, 5'-GCTCTTCCGCTCCTCTCACA-3' and reverse, 5'-GCTTCCTCCTCCCTTCTGGT-3'. The $\beta$-actin primer sequences used as quantitative controls were as follows: Forward, 5'-ATTGCCGACAGGATGCAG-3' and reverse, 5'-CTCAGGAGGAGCAATGATCTT-3' for qPCR; and forward, 5'-GAGGTGATAGCATTGCTTTCG-3' and reverse, 5'-CAA GTCAGTGTACAGGTAAGC-3' for semi-quantitative PCR. 
Table I. A usage list of the breast cancer cell lines.

\begin{tabular}{|c|c|c|c|c|}
\hline Cell line & $\begin{array}{l}\text { Temperature } \\
\left({ }^{\circ} \mathrm{C}\right)\end{array}$ & Atmosphere & Media + supplements & $\begin{array}{l}\text { Analyses } \\
\text { performed }\end{array}$ \\
\hline MDA-MB-231 & 37 & Air, $100 \%$ & Leibovitz's L- $15+10 \%$ FBS with $1 \% \mathrm{Ab}$ & qPCR, pyrosequencing \\
\hline HCC1143 & 37 & Air, $95 \% ; \mathrm{CO}_{2}, 5 \%$ & RPMI-1640 + 10\% FBS with $1 \%$ Ab & qPCR, pyrosequencing \\
\hline BT-20 & 37 & Air, $95 \% ; \mathrm{CO}_{2}, 5 \%$ & MEM + $10 \%$ FBS with $1 \%$ Ab & $\begin{array}{l}\text { qPCR, pyrosequencing, } \\
\text { bisulfite-sequencing }\end{array}$ \\
\hline BT-549 & 37 & Air, $95 \% ; \mathrm{CO}_{2}, 5 \%$ & RPMI- $1640+10 \%$ FBS with $1 \%$ Ab & qPCR \\
\hline HCC 1395 & 37 & Air, $95 \% ; \mathrm{CO}_{2}, 5 \%$ & RPMI-1640 + 10\% FBS with $1 \%$ Ab & qPCR \\
\hline HCC1937 & 37 & Air, $95 \% ; \mathrm{CO}_{2}, 5 \%$ & RPMI- $1640+10 \%$ FBS with $1 \%$ Ab & $\begin{array}{l}\text { qPCR, pyrosequencing, } \\
\text { bisulfite-sequencing }\end{array}$ \\
\hline MDA-MB-157 & 37 & Air, $100 \%$ & Leibovitz's L- $15+10 \%$ FBS with $1 \% \mathrm{Ab}$ & qPCR, pyrosequencing \\
\hline HCC38 & 37 & Air, $95 \% ; \mathrm{CO}_{2}, 5 \%$ & RPMI- $1640+10 \%$ FBS with $1 \%$ Ab & qPCR \\
\hline $\mathrm{HCC} 70$ & 37 & Air, $95 \% ; \mathrm{CO}_{2}, 5 \%$ & RPMI- $1640+10 \%$ FBS with $1 \%$ Ab & $\begin{array}{l}\text { qPCR, pyrosequencing, } \\
\text { bisulfite-sequencing }\end{array}$ \\
\hline MDA-MB-468 & 37 & Air, $100 \%$ & Leibovitz's L-15 + 10\% FBS with $1 \%$ Ab & qPCR \\
\hline BT-474 & 37 & Air, $95 \% ; \mathrm{CO}_{2}, 5 \%$ & MEM + $10 \%$ FBS with $1 \% \mathrm{Ab}$ & qPCR, pyrosequencing \\
\hline MDA-MB-453 & 37 & Air, $100 \%$ & Leibovitz's L-15 + 10\% FBS with $1 \% \mathrm{Ab}$ & qPCR, pyrosequencing \\
\hline SK-BR3 & 37 & Air, $95 \% ; \mathrm{CO}_{2}, 5 \%$ & McCoy's $5 \mathrm{a}+10 \%$ FBS with $1 \%$ Ab & qPCR \\
\hline $\mathrm{T}-47 \mathrm{D}$ & 37 & Air, $95 \% ; \mathrm{CO}_{2}, 5 \%$ & RPMI- $1640+10 \%$ FBS with $1 \%$ Ab & qPCR \\
\hline ZR-75-1 & 37 & Air, $95 \% ; \mathrm{CO}_{2}, 5 \%$ & RPMI- $1640+10 \%$ FBS with $1 \%$ Ab & qPCR \\
\hline KPL-3C & 37 & Air, $95 \% ; \mathrm{CO}_{2}, 5 \%$ & RPMI-1640 + 10\% FBS with $1 \%$ Ab & qPCR \\
\hline MCF-7 & 37 & Air, $95 \% ; \mathrm{CO}_{2}, 5 \%$ & $\begin{array}{l}\text { MEM + } 10 \% \text { FBS with } 1 \% \mathrm{Ab} \\
0.1 \mathrm{mM} \text { NEAA, } 1 \mathrm{mM} \text { sodium } \\
\text { pyruvate and } 10 \mu \mathrm{g} / \mathrm{ml} \text { insulin }\end{array}$ & qPCR \\
\hline
\end{tabular}

RPMI-1640 medium, FBS and insulin were obtained from Sigma-Aldrich; Merck KGaA (Darmstadt, Germany). Leibovitz's L-15, MEM, McCoy's 5a, NEAA and sodium pyruvate were purchased from Thermo Fisher Scientific, Inc. (Waltham, MA, USA). Ab-antimycotic (Thermo Fisher Scientific, Inc.) included penicillin, streptomycin and amphotericin B. FBS, fetal bovine serum; MEM, minimal essential medium; NEAA, Non-Essential Amino Acids; Ab, antibody; qPCR, quantitative polymerase chain reaction.

Methylation analysis using bisulfite pyrosequencing and bisulfite sequencing. Genomic DNA $(1 \mu \mathrm{g})$ extracted from clinical samples and cell lines was modified with sodium bisulfite using an EpiTect Bisulfite kit (Qiagen $\mathrm{GmbH}$ ), subsequent to which bisulfite pyrosequencing was performed as previously described (24). The methylation ratio (\%) of LRRC26 in each sample was analyzed using PyroMark Q96 software version 2.5.8 (Qiagen $\mathrm{GmbH}$ ). For bisulfite sequencing, thermocycling conditions were $10 \mathrm{~min}$ at $94^{\circ} \mathrm{C}$, followed by 45 cycles of denaturation at $94^{\circ} \mathrm{C}$ for $1 \mathrm{~min}$, annealing at $60^{\circ} \mathrm{C}$ for $1 \mathrm{~min}$ and extension at $72^{\circ} \mathrm{C}$ for $10 \mathrm{~min}$. Amplified PCR products were cloned into the $\mathrm{pCR} 2.1-\mathrm{TOPO}$ vector (Thermo Fisher Scientific, Inc.), and 11 clones from HCC1937, 12 clones from BT-20 and 15 clones from HCC70 were sequenced using an ABI3130x automated sequencer (Thermo Fisher Scientific, Inc.). Primer sequences and PCR product sizes are listed in Table III.

5'-aza-dC treatment. To restore epigenetically silenced LRRC26 gene expression, HCC1937 cells were plated onto 6 -well dishes at a density of $3.5 \times 10^{5}$ cells/well and treated with several concentrations $(0,1,2.5,5$ and $10 \mu \mathrm{M})$ of $5^{\prime}$-aza-dC (Sigma-Aldrich; Merck KGaA, Darmstadt, Germany) for 5 days, replacing the reagent and RPMI-1640 (Sigma-Aldrich;
Merck KGaA) medium every 24 h. LRRC26 gene expression following treatment with 5 '-aza-dC was monitored by semi-quantitative PCR as aforementioned.

Small interfering RNA (siRNA)-mediated gene silencing. ON-TARGETplus siRNA-SMARTpool (4 types of siRNA; catalog no.L-029447-01-0005; GEHealthcareDharmacon,Inc., Lafayette, CO, USA) was used to knockdown LRRC26 expression in the HCC70 cells, with siRNA against enhanced green fluorescent protein (si-EGFP) used as a control. HCC70 cells were plated in 6 -well dishes at $1.0 \times 10^{5}$ cells/well. Transfection of $10 \mathrm{nM}$ ON-TARGETplus siRNAs was performed using Lipofectamine RNAiMax (Thermo Fisher Scientific, Inc.) according to the manufacturer's protocols. Knockdown efficiency was evaluated by qPCR using the aforementioned protocol at 48, 72, 96 and $120 \mathrm{~h}$ post-transfection. Cell proliferation assays were performed using Cell Counting Kit-8 (Dojindo Molecular Technologies, Inc., Kumamoto, Japan) as previously described (20). All experiments were performed in triplicate.

Soft agar colony formation assay. Anchorage-independent growth was assessed by the soft agar assay. HCC70 cells were transfected with $10 \mathrm{nM}$ ON-TARGETplus siRNAs for $36 \mathrm{~h}$, 
Table II. Clinical and pathological features of 26 triple-negative breast cancer cases enrolled in RNA-seq and qPCR analyses.

\begin{tabular}{|c|c|c|c|c|c|c|c|c|}
\hline Case_ID & Age (years) & Gender & ER & $\operatorname{PgR}$ & HER2 & Histology & T-stage & Node \\
\hline 10 & 57 & $\mathrm{~F}$ & $(-)$ & $(-)$ & $1^{+}$ & Papillotubular $>$scirrhous & $\mathrm{T} 2$ & + \\
\hline $19^{\mathrm{a}}$ & 44 & $\mathrm{~F}$ & $(-)$ & $(-)$ & 0 & Papillotubular & $\mathrm{T} 1$ & - \\
\hline 36 & 50 & $\mathrm{~F}$ & $(-)$ & $(-)$ & 0 & Solid-tubular $>$ papillotubular & $\mathrm{T} 2$ & + \\
\hline $53^{\mathrm{a}}$ & 55 & $\mathrm{~F}$ & $(-)$ & $(-)$ & 0 & Papillotubular $>$ scirrhous & $\mathrm{T} 1$ & - \\
\hline $54^{\mathrm{a}}$ & 77 & $\mathrm{~F}$ & $(-)$ & $(-)$ & 0 & Solid-tubular & $\mathrm{T} 1$ & - \\
\hline $56^{\mathrm{a}}$ & 58 & $\mathrm{~F}$ & $(-)$ & $(-)$ & 0 & Solid-tubular & $\mathrm{T} 1$ & + \\
\hline 101 & 60 & $\mathrm{~F}$ & $(-)$ & $(-)$ & 0 & Scirrhous $>$ solid-tubular & $\mathrm{T} 2$ & + \\
\hline $110^{\mathrm{a}}$ & 77 & $\mathrm{~F}$ & $(-)$ & $(-)$ & $1^{+}$ & Scirrhous $>$papillotubular & $\mathrm{T} 2$ & + \\
\hline $114^{\mathrm{a}}$ & 76 & $\mathrm{~F}$ & $(-)$ & $(-)$ & 0 & Solid-tubular & $\mathrm{T} 2$ & + \\
\hline 133 & 50 & $\mathrm{~F}$ & $(-)$ & $(-)$ & 0 & Solid-tubular & $\mathrm{T} 1$ & - \\
\hline $150^{\mathrm{a}}$ & 58 & $\mathrm{~F}$ & $(-)$ & $(-)$ & 0 & Papillotubular & $\mathrm{T} 2$ & - \\
\hline $159^{\mathrm{a}}$ & 75 & $\mathrm{~F}$ & $(-)$ & $(-)$ & $1^{+}$ & Papillotubular & $\mathrm{T} 1$ & - \\
\hline 171 & 37 & $\mathrm{~F}$ & $(-)$ & $(-)$ & $1^{+}$ & Solid-tubular & $\mathrm{T} 1$ & + \\
\hline $179^{\mathrm{a}}$ & 61 & $\mathrm{~F}$ & $(-)$ & $(-)$ & 0 & Solid-tubular & $\mathrm{T} 2$ & - \\
\hline 188 & 50 & $\mathrm{~F}$ & $(-)$ & $(-)$ & $1^{+}$ & Solid-tubular $>$scirrhous & $\mathrm{T} 1$ & - \\
\hline $192^{\mathrm{a}}$ & 50 & $\mathrm{~F}$ & $(-)$ & $(-)$ & 0 & Solid-tubular & $\mathrm{T} 1$ & + \\
\hline $209^{\mathrm{a}}$ & 50 & $\mathrm{~F}$ & $(-)$ & $(-)$ & 0 & Solid-tubular $>$ scirrhous & $\mathrm{T} 2$ & + \\
\hline 242 & 58 & $\mathrm{~F}$ & $(-)$ & $(-)$ & 0 & Unknown (large cell) & $\mathrm{T} 3$ & + \\
\hline $270^{\mathrm{a}}$ & 47 & $\mathrm{~F}$ & $<5$ & $<5$ & 0 & Solid-tubular & $\mathrm{T} 1$ & - \\
\hline $272^{\mathrm{a}}$ & 88 & $\mathrm{~F}$ & $<5$ & $<5$ & 0 & Solid-tubular & $\mathrm{T} 2$ & - \\
\hline $284^{\mathrm{a}}$ & 58 & $\mathrm{~F}$ & $(-)$ & $(-)$ & 0 & Papillotubular & $\mathrm{T} 2$ & + \\
\hline $292^{\mathrm{a}}$ & 69 & $\mathrm{~F}$ & $<5$ & $<5$ & 0 & Solid-tubular $>$ scirrhous & $\mathrm{T} 2$ & + \\
\hline 306 & 83 & $\mathrm{~F}$ & $<5$ & $<5$ & $1^{+}$ & Invasive lobular & $\mathrm{T} 2$ & - \\
\hline 320 & 70 & $\mathrm{~F}$ & $(-)$ & $(-)$ & 0 & Scirrhous $>$ papillotubular & $\mathrm{T} 1$ & - \\
\hline 329 & 32 & $\mathrm{~F}$ & $<5$ & $<5$ & 0 & Papillotubular & $\mathrm{T} 1$ & - \\
\hline 334 & 63 & $\mathrm{~F}$ & $<5$ & $<5$ & 0 & Adenoid cystic & $\mathrm{T} 1$ & - \\
\hline
\end{tabular}

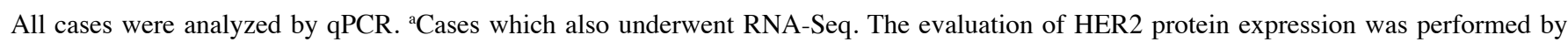
immunohistochemistry assay of the invasive component of a breast cancer specimen (41). TNM classification was classified by General Rules for Clinical and Pathological Recording of Breast Cancer edited by the Japanese Breast Cancer Society that referred to the International Union Against Cancer (42). qPCR, quantitative polymerase chain reaction; RNA-Seq, RNA sequencing; ER, estrogen receptor; PgR, progesterone receptor; HER2, human epidermal growth factor receptor 2; F, female.

Table III. Primer sequences used for bisulfite pyrosequencing and bisulfite sequencing of LRRC26.

\begin{tabular}{ll}
\hline Primer & \multicolumn{1}{c}{ Primer sequences } \\
\hline Bisulfite pyrosequence & \\
Forward primer (Seq.1-2) & TGGGCGGTGTTTTGTTGTTTAGGTTA \\
Reverse primer (Seq.1-2) & Bio_AAAACTCCAAACTACTCTTAACTCAAC \\
Forward primer (Seq.TCGA) & AGGTTTTATTTAGTATGGGAATGGGATT \\
Reverse primer (Seq.TCGA) & Bio_AACCCAAAAATCCTACTCCTCACCC \\
Sequencing primer (Seq.1) & TTGTTTAGGTTAGGGTT \\
Sequencing primer (Seq.2) & GAGGTGGTTTTGATAG \\
Sequencing primer (Seq.TCGA) & GGAATGGGATTATTTTTG \\
Sequence to analyze (Seq.1) & CGGCGGGCG \\
Sequence to analyze (Seq.2) & CGTTGTGGTCGGCG \\
Sequence to analyze (Seq.TCGA) & CGTGGGGGTTATTTCGTATGTGTACG \\
Bisulfite sequence & \\
Forward primer (Seq.1-2) & TGGGCGGTGTTTTGTTGTTTAGGTTA \\
Reverse primer & AACCCCGCATAAAAACAACCCCCC \\
\hline
\end{tabular}

Reverse primers of bisulfite pyrosequence are 5'-biotinylated. Underlining indicates a possible CpG site of LRRC26. LRRC26, leucine-rich repeat-containing 26 . 
and $2.5 \times 10^{3}$ cells were plated in triplicate in $5 \mathrm{ml}$ RPMI-1640 medium containing $0.4 \%$ soft agarose, overlaid on $5 \mathrm{ml} 0.72 \%$ agarose in $6-\mathrm{cm}$ dishes and cultured at $37^{\circ} \mathrm{C}$ for 11 days. Colonies per well were counted on a Power IX71 microscope (Olympus Corporation, Tokyo, Japan).

Migration assay. BD Falcon Cell Culture Inserts (24 wells, $8-\mu \mathrm{m}$ pore size; BD Biosciences, Franklin Lakes, NJ, USA) were rehydrated with serum-free RPMI-1640 at $37^{\circ} \mathrm{C}$ in a $5 \%$ $\mathrm{CO}_{2}$ incubator for $2 \mathrm{~h}$. Following rehydration, the medium was removed and $0.5 \mathrm{ml}$ RPMI-1640 was added to the upper chamber, and $0.5 \mathrm{ml}$ RPMI-1640 with $10 \%$ fetal bovine serum (FBS) was added to the lower chamber. RPMI/FBS medium $(0.5 \mathrm{ml})$ containing $2.5 \times 10^{4} \mathrm{HCC} 70$ cells previously transfected with siRNA for $36 \mathrm{~h}$ was added to each insert. The HCC70 cells in the migration chamber underwent incubation at $37^{\circ} \mathrm{C}$ for $48 \mathrm{~h}$. Following incubation, the chamber inserts were fixed (4\% paraformaldehyde for $10 \mathrm{~min}$ ) prior to being stained with $1 \%$ Giemsa at room temperature for 2 days. The total number of migrated cells for each treatment was calculated from five random fields for each insert counted on a Power IX71 microscope (Olympus Corporation) at x40 magnification. The number of migrated cells per well for each treatment was averaged from duplicate samples and expressed as the mean \pm standard deviation.

Invasion assay. Matrigel invasion chambers (24 wells, $8-\mu \mathrm{m}$ pore size; Corning Inc., Corning, NY, USA) were rehydrated with serum-free RPMI at $37^{\circ} \mathrm{C}$ in a $5 \% \mathrm{CO}_{2}$ incubator for $2 \mathrm{~h}$. Following rehydration, the medium was removed and $0.5 \mathrm{ml}$ RPMI-1640 was added to the upper chamber, and $0.5 \mathrm{ml}$ RPMI-1640 plus $10 \%$ FBS was added to the lower chamber. RPMI/FBS medium $(0.5 \mathrm{ml})$ containing $2.5 \times 10^{4} \mathrm{HCC} 70$ cells previously transfected with siRNA for $36 \mathrm{~h}$ was added to each insert. The HCC70 cells in the invasion chamber were incubated at $37^{\circ} \mathrm{C}$ for $48 \mathrm{~h}$. Following incubation, chamber inserts were fixed with $4 \%$ paraformaldehyde for $10 \mathrm{~min}$ prior to being stained with $1 \%$ Giemsa at room temperature for 2 days. The total number of migrated cells for each treatment was calculated from five random fields for each insert counted on a Power IX71 microscope (Olympus Corporation) at $x 40$ magnification. The number of invaded cells per well for each treatment was averaged from duplicate samples and expressed as the mean \pm standard deviation.

Construction of expression vectors. pCAGGSSnHC and pCAGGSn3FC, in which an HA-tag and a 3xFLAG-tag, respectively, are inserted in the $\mathrm{C}$-terminus of the cloning sites of pCAGGS vector, were constructed and gifted by Dr Yusuke Nakamura (University of Tokyo, Tokyo, Japan). Briefly, to construct the $L R R C 26$ and B cell receptor associated protein 31 (BAP31) expression vectors, the entire coding sequences of LRRC26 and BAP31 cDNAs were amplified by PCR using KOD-Plus DNA polymerase (Toyobo, Osaka, Japan) with the following primers: $L R R C 26$ forward, 5'-GGAATTCAT GCGGGGCCCTTCCTGGTCG-3' and reverse, 5'-CCG CTCGAGGGCTTGGGCGGCAGCGGCGG-3'; and BAP31 forward, 5'-CGGAATTCACCATGGGTGCCGAGGCGTC CTC-3' and reverse, 5'-CCGCTCGAGCTCTTCCTTCTTGT CCATGGGAC-3' (bold indicates the restriction enzyme sites).
The thermocycling conditions were as follows: For $L R R C 26$, an initial denaturation of $2 \mathrm{~min}$ at $94^{\circ} \mathrm{C}$, followed by 35 cycles of denaturation at $94^{\circ} \mathrm{C}$ for $15 \mathrm{sec}$, annealing at $62^{\circ} \mathrm{C}$ for $30 \mathrm{sec}$ and elongation at $68^{\circ} \mathrm{C}$ for $80 \mathrm{sec}$; for BAP31, an initial denaturation of $2 \mathrm{~min}$ at $94^{\circ} \mathrm{C}$, followed by 30 cycles of denaturation at $94^{\circ} \mathrm{C}$ for $15 \mathrm{sec}$, annealing at $52^{\circ} \mathrm{C}$ for $30 \mathrm{sec}$ and elongation at $68^{\circ} \mathrm{C}$ for $1 \mathrm{~min}$. BAP31 is an a transmembrane protein associated with the endoplasmic reticulum (ER) and ER-Golgi intermediates, and has been involved in apoptosis and protein trafficking $(25,26)$. Each PCR product was inserted into the EcoRI and XhoI sites of pCAGGSnHA in frame with the C-terminal HA-tag (pCAGGSSnHC-LRRC26) and pCAGGSn3FC in frame with the C-terminal FLAG-tag (pCAGGSSn3FC-BAP31), respectively. To construct the pGL3$\mathrm{NF}-\kappa \mathrm{B}$ expression vector for the luciferase reporter assay as described next, the oligonucleotides for NF- $\kappa \mathrm{B}-\mathrm{U}$ (5'-CTGGGG ACTTTCCGCTGGGGACTTTCCGCTGGGGACTTTCCGC TGGGGACTTTCCGCTATATAC-3') and NF-кB-L (5'-TCGAG TATATAGCGGAAAGTCCCCAGCGGAAAGTCCCCAGCG GAAAGTCCCCAGCGGAAAGTCCCCAGGTAC-3') (bold font indicates restriction enzyme sites and underlining indicates $4 \mathrm{x}$ NF- $\kappa \mathrm{B}$ binding sites) was annealed, and cloned into the KpnI and XhoI sites of pGL3-basic (Promega Corporation, Madison, WI, USA). The DNA sequence of all constructs were confirmed by DNA sequencing (ABI3500xL; Thermo Fisher Scientific, Inc.).

Luciferase reporter assay. $293 \mathrm{~T}$ cells $\left(2.0 \times 10^{5}\right.$ cells/well in 6-well plates) were co-transfected with $200 \mathrm{ng}$ pGL3-NF- $\kappa \mathrm{B}$ in combination with $1.0 \mu \mathrm{g}$ pCAGGSnHC-LRRC26 or the mock vector using Fugene 6 (Promega Corporation). pRL-TK (Promega Corporation) was used as an internal control. After $24 \mathrm{~h}$, the cells were treated with TNF- $\alpha(40 \mathrm{ng} / \mathrm{ml}$; Sigma-Aldrich; Merck KGaA) for 0, 4, 8 and $12 \mathrm{~h}$. Next, the cells were harvested and analyzed for Firefly luciferase and Renilla luciferase activity using the PicaGene Dual Sea Pansy Luminescence kit (Wako Pure Chemical Industries, Ltd., Osaka, Japan) according to the manufacturer's protocols. Data are expressed as the fold increase over mock-transfected cells (set at 1.0) and represented as the mean \pm standard error of two independent experiments.

Analysis of public database of RNA expression and methylation in breast cancer. Publicly available gene expression and methylation data from The Cancer Genome Atlas (TCGA; http://cancergenome.nih.gov/) were downloaded. Differential expression (by fold-change value) between breast cancer and the adjacent normal breast tissues was calculated according to the normalized gene expression value of each sample.

Microarray analysis. HCC70 cells were seeded at a density of $2 \times 10^{5}$ cells/well onto 6 -well plates, followed by transfection with $10 \mathrm{nM}$ siEGFP (Sigma-Aldrich; Merck KGaA) or siLRRC26 (GE Heathcare Dharmacon, Inc.) using Lipofectamine RNAiMAX (Thermo Fisher Scientific, Inc.) according to the manufacturer's protocols. After 48 and $72 \mathrm{~h}$ of siRNA transfection, total RNA was extracted using a NucleoSpin RNA kit (Takara Bio, Inc.) according to the manufacturer's protocols. A total of $100 \mathrm{ng}$ total RNA from each sample was amplified and Cy3-labeled. Next, $0.825 \mu \mathrm{g}$ Cy3-labeled cRNA was fragmented, hybridized onto the 
Agilent SurePrint G3 Hmn GE 8x60K Ver 2.0 platform (Agilent Technologies, Inc.) and then incubated with rotation at $65^{\circ} \mathrm{C}$ for $17 \mathrm{~h}$. Data were analyzed using GeneSpring software version 13.0 (Agilent Technologies, Inc.) as previously described (20). To identify genes that were significantly altered between siLRRC26-treated cells and siEGFP-treated cells, the mean signal intensity values in each analysis were compared. The extent and direction of the differential expression between 48 and $72 \mathrm{~h}$ were determined by calculating the fold-change value. Data from this microarray analysis have been submitted to the NCBI Gene Expression Omnibus archive as series GSE90582.

Functional gene annotation clustering. The Database for Annotation, Visualization and Integrated Discovery (DAVID 6.8) was approved to detect functional gene annotation clusters based on gene expression profiling by gene annotation enrichment analysis (http://david.abcc.ncifcrf.gov/) (27,28). The clusters from the gene annotation enrichment analysis were selected in this study based on a previous study (29).

Scratch wound cell migration and invasion assays by IncuCyte. BT20 cells (2.0×10 5 cells/well in 6-well plates) were transfected with $2.0 \mu \mathrm{g}$ pCAGGSnHC-LRRC26 or the mock vector. For migration assay, after $48 \mathrm{~h}$, cells $\left(2.5 \times 10^{4}\right.$ cells/well $)$ were re-seeded onto the 96-well ImageLock ${ }^{\mathrm{TM}}$ plate (Essen BioScience, Ann Arbor, MI, USA), which was coated with Matrigel $(100 \mu \mathrm{g} / \mathrm{ml})$ prior to seeding the cells. After $4 \mathrm{~h}$, the wound area was created in the cell monolayer with a 96-well WoundMaker ${ }^{\mathrm{TM}}$ (Essen BioScience). The plate was washed with phosphate-buffered saline (PBS) (-) to remove detached cells, and $100 \mu \mathrm{l}$ fresh medium was added. For the invasion assay, the cells were covered with $50 \mu \mathrm{l}$ Matrigel solution $(8 \mathrm{mg} / \mathrm{ml})$ and incubated for $30 \mathrm{~min}$. Next, $100 \mu \mathrm{l}$ of additional culture media was added to each well and the plates were placed into the IncuCyte ZOOM (Essen Bioscience). The two plate types were scanned every $2 \mathrm{~h}$ for $72 \mathrm{~h}$. Data were analyzed using ZOOM software version 2016B (Essen BioScience) according to the manufacturer's protocols. Cell migration and invasion were expressed as relative wound density.

Immunocytochemical staining analysis. To examine the subcellular localization of the $L R R C 26$ protein in TNBC cells, BT20 cells $\left(2.0 \times 10^{5}\right.$ cells/well in 6 -well plates $)$ were transfected with $2.0 \mu \mathrm{g}$ pCAGGSnHC-LRRC26 or the mock vector using FuGENE HD transfection regent (Roche Diagnostics $\mathrm{GmbH}$, Mannheim, Germany). In addition, BT-20 cells were co-transfected with $2.0 \mu \mathrm{g}$ pCAGGSnHC-LRRC26 and pCAGGSn3FC-BAP31 or the empty vector (Mock). At $48 \mathrm{~h}$ post-transfection, BT-20 cells $\left(2.0 \times 10^{4}\right.$ cells/well $)$ were plated onto an 8-well glass slide chamber (Thermo Fisher Scientific, Inc.). After $24 \mathrm{~h}$ of incubation, the cells were fixed with $4 \%$ paraformaldehyde for $30 \mathrm{~min}$ at $4^{\circ} \mathrm{C}$ and then peameabilized with $0.1 \%$ Triton $\mathrm{X}-100$ for $2 \mathrm{~min}$ at room temperature. Next, the cells were covered with $3 \%$ bovine serum albumin for $1 \mathrm{~h}$ at room temperature and then incubated with anti-HA antibody (1:1,000 dilution; cat. no. 1867423; Roche Diagnostics GmbH) and anti-FLAG M2 (1:1,000 dilution; cat. no. F-3165; SigmaAldrich;Merck KGaA) or anti-78-kDa glucose-regulated protein (GRP78; 1:200 dilution; cat. no. ab108615; Abcam, Cambridge,
UK) antibodies overnight at $4^{\circ} \mathrm{C}$. Subsequent to washing with PBS (-), the cells were stained with Alexa 488-conjugated antirat (cat. no. A-21210) and Alexa 594-conjugated anti-mouse (cat. no. A-11032) or anti-rabbit (cat. no. A-11037) antibodies (1:1,000 dilution; Molecular Probes; Thermo Fisher Scientific, Inc.) at room temperature for $1 \mathrm{~h}$, respectively. The nuclei were stained with 4',6'-diamidine-2'-phenylindole dihydrochloride. Fluorescence was observed was obtained using an IX71 microscope (Olympus Corporation). Scale bars indicate $20 \mu \mathrm{m}$.

Immunoblotting analyses. Immunoblotting analyses were conducted as previously described (30). Briefly, cell lysates were prepared with lysis buffer at $48 \mathrm{~h}$ post-transfection. The lysates were electrophoresed, transferred to a nitrocellulose membrane and blocked with $4 \%$ BlockAce solution (Dainippon Sumimoto Pharma Co., Ltd., Osaka, Japan) for $1 \mathrm{~h}$. Subsequently, the membrane were incubated with anti-HA (1:3,000 dilution; cat. no. 1867423) and anti- $\alpha / \beta$-Tubulin antibodies (1:1,000 dilution; cat. no. 2148) (Cell Signaling Technology, Inc., Danvers, MA, USA) at $4^{\circ} \mathrm{C}$ overnight, respectively. Following incubation with a horseradish peroxidase-conjugated secondary antibody (1:5,000 dilution; catalog no. sc-2006 for anti-rat antibody; catalog no. sc-2004 for anti-rabbit antibody; Santa Cruz Biotechnology, Inc., Dallas, TX, USA) at room temperature for $1 \mathrm{~h}$, the membranes were developed with an enhanced chemiluminescence system (GE Healthcare Life Sciences, Little Chalfont, UK) and were scanned using an Image Reader LAS-3000 mini (Fujifilm, Tokyo, Japan).

Statistical analysis. Statistical significance was calculated using the Kruskal-Wallis test and Dunnett's post-hoc test with SPSS version 20.0 software (IBM, Armonk, NY, USA) for the comparison between the gene expression and methylation levels from the TCGA dataset. For multiple comparisons of Figs. 1D and 2B, a one-way analysis of variance with Dunnett's and Tukey's post hoc tests, respectively, were performed. Wilcoxon signed rank test was performed using JMP 12.1.0 (SAS Institute Japan, Ltd., Tokyo, Japan) to assess methylation levels between tumor and paired normal tissues. The $\chi^{2}$ test was performed using Microsoft ${ }^{\circledR}$ Excel 2016 to assess the associations between the expression of the LRRC26 gene and patient characteristics. Student's two-sided t-test was performed using Microsoft ${ }^{\circledR}$ Excel 2016 to calculate statistical significance in experiments for the gene expression, methylation status, colony formation, migration, invasion and luciferase activity. $\mathrm{P}<0.05$ was considered to indicate a statistically significant difference.

\section{Results}

LRRC26 is specifically downregulated in TNBC clinical specimens and cell lines due to methylation of CpG islands. To characterize the molecular features of TNBC, RNA-seq analysis was first performed and it was found that $L R R C 26$ expression was downregulated in 10 out of 15 patients with TNBC, but upregulated in 4 (no regulation change in 1 patient) (Fig. 1A). Subsequent qPCR confirmed that $L R R C 26$ was significantly downregulated in 16 out of the 26 patients with TNBC ( 6 of the 15 patients who also underwent RNA-Seq) 
Table IV. Association between leucine-rich repeat-containing 26 downregulation in triple-negative breast cancer cases and patient characteristics.

\begin{tabular}{|c|c|c|c|c|}
\hline Characteristic & Total & $\begin{array}{l}\text { Expression of } L R R C 26 \text { for } \\
\text { tumor/normal tissue }<1.0\end{array}$ & $\begin{array}{l}\text { Expression of } L R R C 26 \text { for } \\
\text { tumor/normal tissue } \geq 1.0\end{array}$ & $\begin{array}{l}\text { P-value } \\
\left(\chi^{2} \text { test }\right)\end{array}$ \\
\hline Total, n & 26 & $17(65.4)$ & $9(34.6)$ & \\
\hline Age in years, n (\%) & & & & 0.482 \\
\hline$\geq 50$ & $22(84.6)$ & $15(57.7)$ & $7(26.9)$ & \\
\hline$<50$ & $4(15.4)$ & $2(7.7)$ & $2(7.7)$ & \\
\hline Menopause, n (\%) & & & & 0.743 \\
\hline Post & $16(61.5)$ & $10(38.5)$ & $6(23.0)$ & \\
\hline Pre & $8(30.8)$ & $6(23.1)$ & $2(7.7)$ & \\
\hline $\mathrm{N} / \mathrm{A}$ & $2(7.7)$ & $1(3.85)$ & $1(3.85)$ & \\
\hline Histological grade, $\mathrm{n}(\%)$ & & & & 0.017 \\
\hline 1 & $7(26.9)$ & $2(7.7)$ & $5(19.2)$ & \\
\hline$\geq 2$ & $19(73.1)$ & $15(57.7)$ & $4(15.4)$ & \\
\hline $\mathrm{T}, \mathrm{n}(\%)$ & & & & 0.216 \\
\hline 1 & $13(50.0)$ & $7(27.0)$ & $6(23.0)$ & \\
\hline$\geq 2$ & $13(50.0)$ & $10(38.5)$ & $3(11.5)$ & \\
\hline $\mathrm{N}, \mathrm{n}(\%)$ & & & & 0.340 \\
\hline- & $14(53.9)$ & $8(30.8)$ & $6(23.1)$ & \\
\hline+ & $12(46.1)$ & $9(34.6)$ & $3(11.5)$ & \\
\hline $\mathrm{M}, \mathrm{n}(\%)$ & & & & $\mathrm{N} / \mathrm{A}$ \\
\hline 0 & $26(100.0)$ & $17(65.4)$ & $9(34.6)$ & \\
\hline 1 & 0.0 & 0.0 & 0.0 & \\
\hline
\end{tabular}

TNM classification was judged according to the General Rules for Clinical and Pathological Recording of Breast Cancer (the Japanese Breast Cancer Society) that referred to the International Union Against Cancer (42). T, tumor stage; N, lymph node metastasis status; M, distant metastasis.

compared with that in paired normal breast tissues (Fig. 1B), which was consistent with the RNA-seq results. Subsequently, statistical analysis of the association between $L R R C 26$ expression level and clinicopathological features, including the tumor stage or grade of TNBC cases used for qPCR, was performed, and it was found that LRRC26 downregulation was significantly associated with increased histological grade in patients with TNBC $\left(\mathrm{P}=0.017 ; \chi^{2}\right.$ test) (Table IV). Furthermore, the expression of the LRRC26 gene was examined by the analysis of TCGA dataset, including a much larger number of TNBC cases and normal controls, and it was found that the LRRC26 gene was significantly downregulated in 123 TNBC cases compared with that in 113 normal controls (Fig. 1C). These results suggested the possibility that the downregulation of LRRC26 may be associated with the carcinogenesis of TNBC. Accordingly, the present study focused on understanding the mechanism of LRRC26 downregulation in TNBC, although further analysis of the mechanism of $L R R C 26$ upregulation in breast cancer will be necessary. Next, to determine whether LRRC26 downregulation is associated with $\mathrm{CpG}$ hypermethylation in its promoter region, bisulfite pyrosequencing analysis was performed using a set of 12 TNBC clinical tissues and adjacent normal breast tissues. LRRC26 methylation levels were quantitatively measured at two $\mathrm{CpG}$ islands containing 'Seq.1' and 'Seq.2', located 206 and 158 bp upstream of the transcription start site, respectively (Fig. 1D). The average methylation levels of 'Seq.1' in the tumor and normal tissues was $43.63 \%$ (range, 18.37-62.89\%) and $26.55 \%$ (range, 18.47-40.09\%), respectively, and that of 'Seq.2' in the tumor and normal tissues was $18.79 \%$ (range, 8.52-23.15\%) and $11.63 \%$ (range, 8.86-15.32\%), respectively (Fig. 1D). Accordingly, the methylation levels of the two $\mathrm{CpG}$ islands were significantly higher in 11 out of 12 tumor tissues compared with those in adjacent normal mammary gland tissues (Fig. 1D; Wilcoxon signed-rank test: Seq.1, $\mathrm{P}=0.0015$ and Seq.2, $\mathrm{P}=0.0024$, respectively) (Fig. 1D). To further validate this result, $L R R C 26$ expression levels were analyzed in breast cancer cell lines by qPCR. LRRC26 expression was significantly downregulated in 8 out of 10 TNBC cell lines compared with that in normal mammary glands (Fig. 1E), whereas its expression level was extremely high in all HER2-positive and ER-positive/HER2-negative cell lines (Fig. 1E). Furthermore, $L R R C 26$ methylation status was analyzed in TNBC cell lines, and it was observed that high levels of methylation at the two CpG island sites in LRRC26 were in agreement with LRRC26 expression levels in 4 out of 6 TNBC cell lines (Fig. 1E and F). Low levels of methylation at the two $\mathrm{CpG}$ island sites were in agreement with high levels of LRRC26 expression in the two HER2-positive cell lines, BT-474 and MDA-MB453. Of the remaining TNBC cell lines, $L R R C 26$ was expressed in 


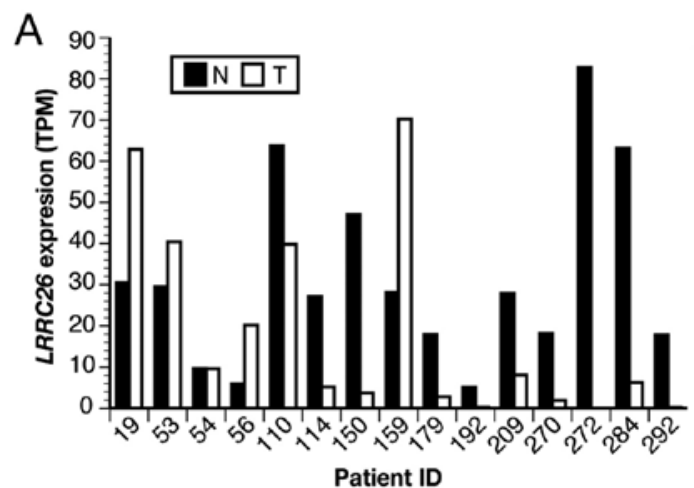

C
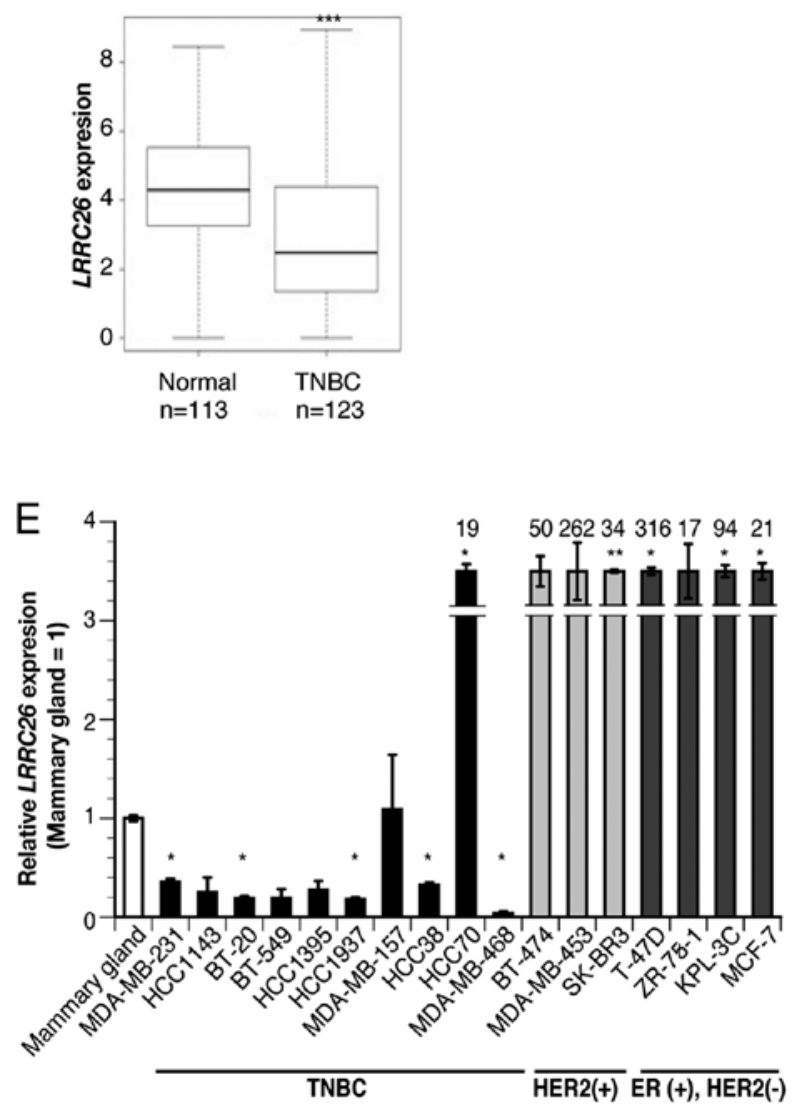

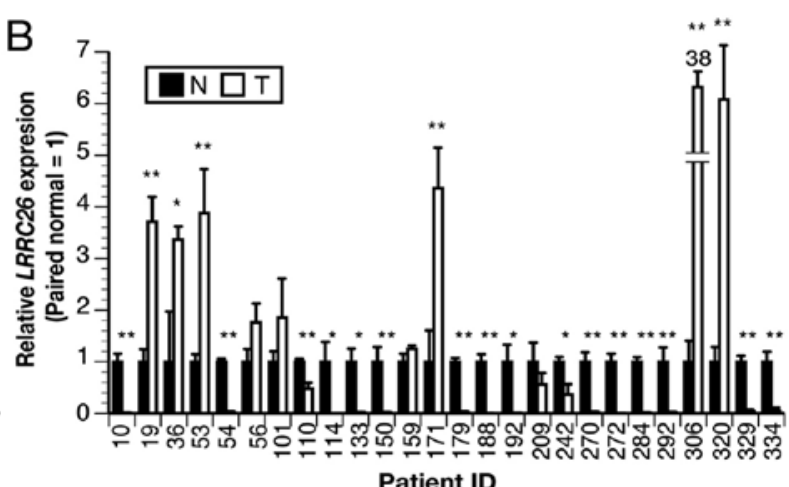

D
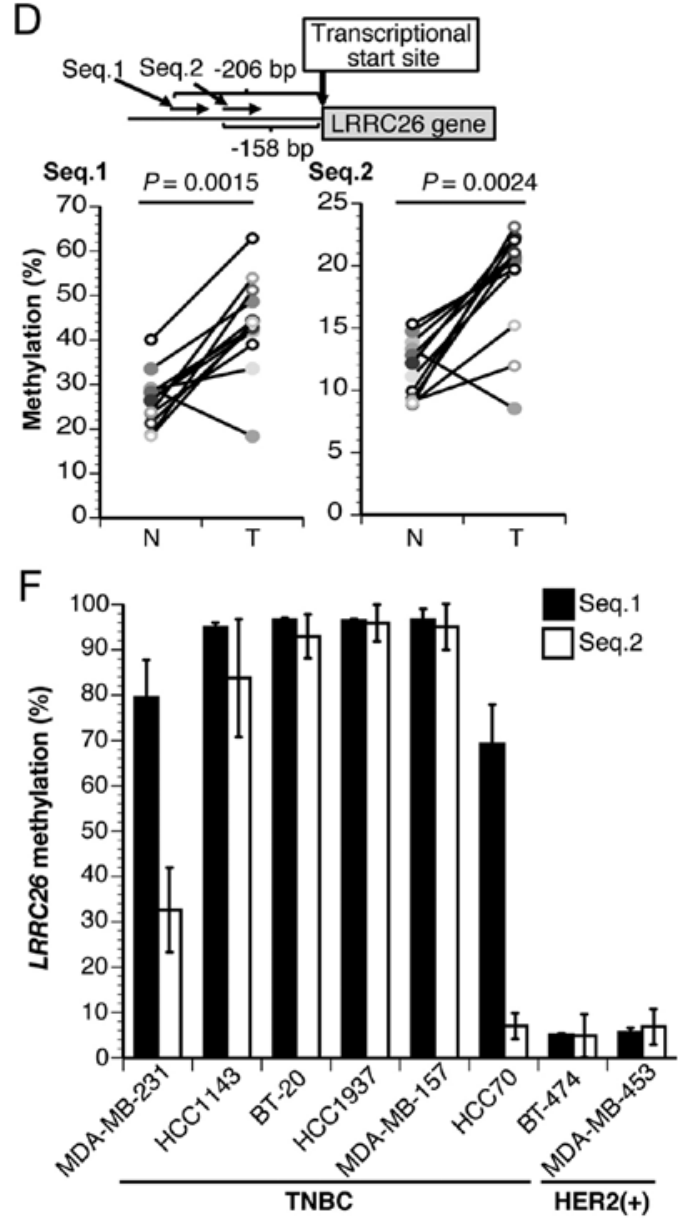

Figure 1. LRRC26 expression and methylation in TNBC. (A) LRRC26 expression determined by RNA-seq analysis of 15 TNBC cases. (B) Relative $L R R C 26$ gene expression in $26 \mathrm{TNBC}$ clinical specimens and paired normal tissues by qPCR. The data represent the mean \pm standard deviation of each condition ( $\mathrm{P}<0.05$ and ${ }^{* *} \mathrm{P}<0.01$; two-sided Student's t-test). (C) Expression levels in 123 TNBC patients and 113 normal tissues obtained from TCGA RNA-seq datasets. The box plot shows the expression level between TNBC and normal tissue. Two-sided Student's t-test revealed a significant difference $\left({ }^{* * *} \mathrm{P}<0.001 \mathrm{vs}\right.$. normal tissues). (D) Diagram of the CpG sites of the LRRC26 gene. The two regions (Seq.1 and Seq.2) analyzed using bisulfite pyrosequencing are shown (upper panel). Bisulfite pyrosequencing analysis of two LRRC26 CpG sites (Seq.1 and Seq.2) in 12 TNBC clinical specimens and paired normal breast tissues (lower panel) (Wilcoxon signed-rank test). (E) Relative expression of LRRC26 gene in 17 breast cancer cell lines, including 10 TNBC, 3 HER2(+) and 4 ER(+) HER2(-) cell lines, compared with that in normal mammary glands, as determined by qPCR. The data represent the mean \pm standard deviation of each condition ("P $<0.05$ and ${ }^{* *} \mathrm{P}<0.01$; analysis of variance with Dunnett's post hoc test). (F) Bisulfite pyrosequencing analysis of 2 LRRC26 CpG sites (Seq.1 and Seq.2) in indicated breast cancer cell lines. The data represent the mean \pm standard deviation of each condition. TNBC, triple-negative breast cancer; TPM, transcript per million; LRRC26, leucine-rich repeat-containing 26; RNA-seq, RNA sequencing; T, clinical tumor specimens; N, normal tissue; ER, estrogen receptor; HER2, human epidermal growth factor receptor 2; qPCR, quantitative polymerase chain reaction.

HCC70, whereas high DNA methylation levels (>60\%) were detected at Seq.1 and low levels at Seq.2. Conversely, LRRC26 was downregulated in MDA-MB-231, which displayed high DNA methylation levels at Seq.1 and moderate levels at Seq.2 (Fig. 1E and F). These results indicated that a different mechanism, such as histone modification or the existence of other critical $\mathrm{CpG}$ sites in the $L R R C 26$ promoter region, may underlie $L R R C 26$ silencing in these cells.

LRRC26 downregulation and hypermethylation occur exclusively in TNBC. To clarify the detailed methylation status, bisulfite sequencing was performed using TNBC cell lines 


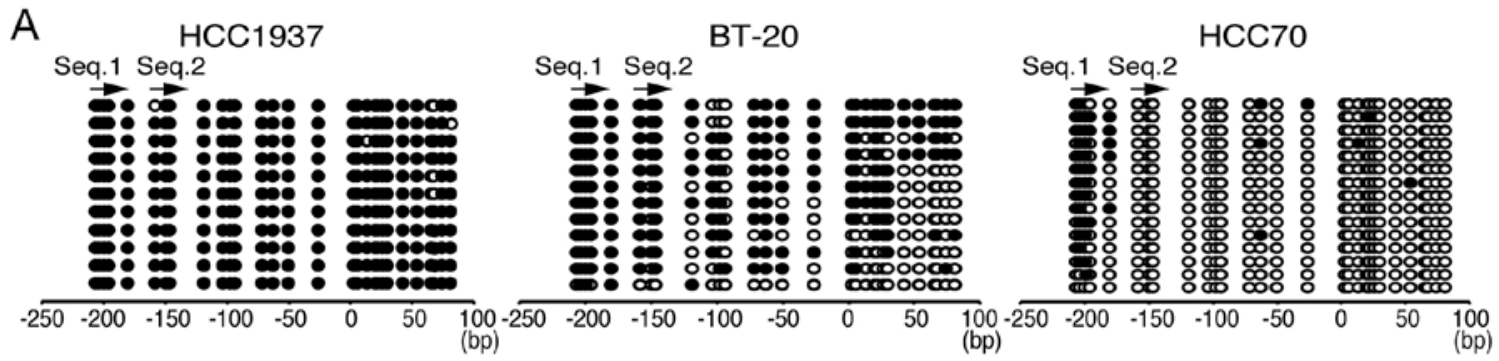

B

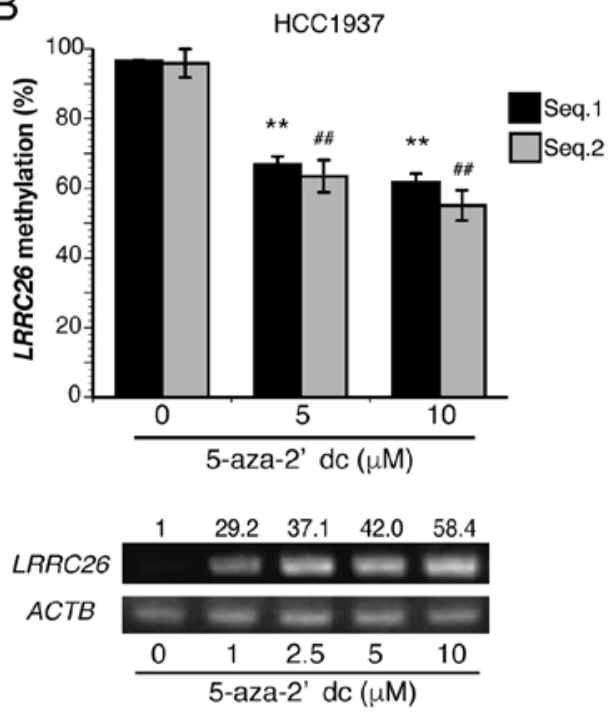

C

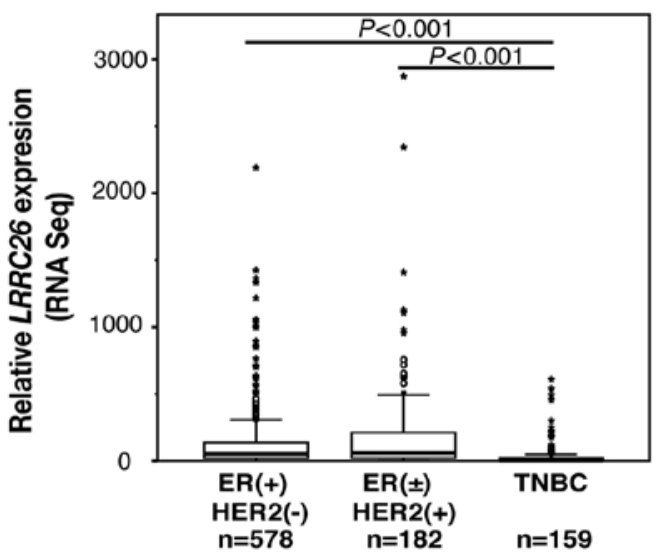

D

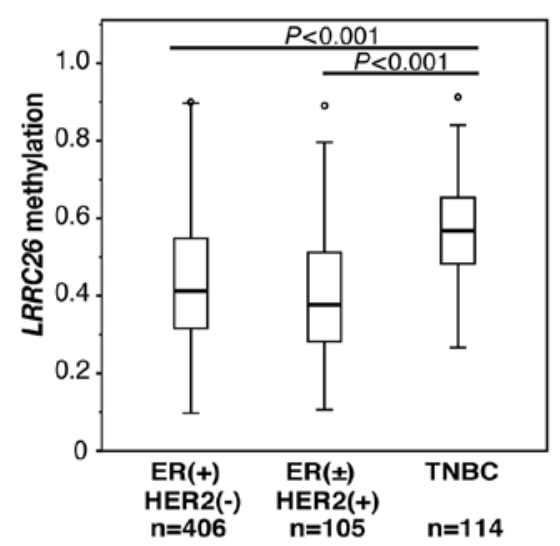

E

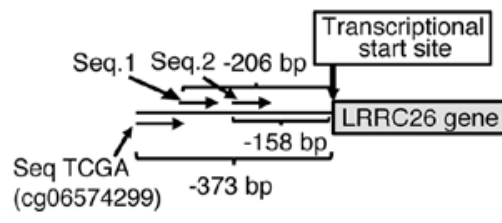

Figure 2. LRRC26 downregulation and hypermethylation are exclusive to TNBC. (A) Bisulfite sequencing analysis of two LRRC26 CpG sites in HCC1937, BT20 and HCC70 cells. Open and filled circles represent unmethylated and methylated CpG sites, respectively. The arrow indicates the region analyzed via bisulfite pyrosequencing. (B) Bisulfite pyrosequencing (bar graph) and semi-quantitative PCR results (bottom panel) for LRRC26 in HCC1937 cells treated with varying doses of 5'-aza-dC for $120 \mathrm{~h}$. Mean methylation levels (\%) of $L R R C 26$ were measured as aforementioned. The data represent the mean \pm standard deviation of methylation levels of each $\mathrm{CpG}$ island. $\left({ }^{* *} \mathrm{P}<0.01\right.$ vs. $5^{\prime}$-aza- $\mathrm{dC}(0 \mu \mathrm{M})$ in Seq.1; ${ }^{\# \#} \mathrm{P}<0.01$ vs. $5^{\text {'-aza- }} \mathrm{dC}(0 \mu \mathrm{M})$ in Seq.2; analysis of variance with Tukey's post hoc test). (C) LRRC26 gene expression in 3 subtypes [ER(+)HER2(-), ER( \pm HER2(+) and TNBC) for cases with TCGA RNA-seq datasets. The Kruskal-Wallis test revealed a significant difference, followed by Dunnett's post hoc test. (D) Methylation levels in 625 breast cancer patients obtained from TCGA datasets. The box plot shows the percent methylation between three breast cancer subtypes classified by ER status and HER 2 expression. The KruskalWallis test revealed a significant difference, followed by Dunnett's post hoc test. (E) Bisulfite pyrosequencing analysis at CpG island SeqTCGA (the CpG island located $373 \mathrm{bp}$ upstream of the transcription start site) in 12 TNBC clinical specimens and paired normal breast tissues (righ panel) (Wilcoxon signed-rank test). The CpG island SeqTCGA site in the LRRC26 gene is also shown (left panel) (Wilcoxon signed-rank test). 5'-aza-dC, 5-aza-2'-deoxycytidine; TNBC, triple-negative breast cancer; $L R R C 26$, leucine-rich repeat-containing 26; ACTB, $\beta$-actin; RNA-seq, RNA sequencing; ER, estrogen receptor; HER2, human epidermal growth factor receptor 2; T, clinical tumor specimens; $\mathrm{N}$, normal tissue; qPCR, quantitative polymerase chain reaction.

HCC1937, BT20 and HCC70. It was found that the 200 bp upstream of the transcription initiation site, including Seq.1 and Seq. $2 \mathrm{CpG}$ islands, in $L R R C 26$ were densely methylated in HCC1937, but not in HCC70, although the Seq.1 CpG island was methylated (Fig. 2A). Moreover, the same regions in $L R R C 26$ were partially methylated in BT20, indicating that the methylation levels at the $L R R C 26$ promoter region were in agreement with the level of $L R R C 26$ expression in all 
three cell lines. Notably, LRRC26 expression was restored in a dose-dependent manner following treatment with 5'-aza-dC in HCC1937 (Fig. 2B). Moreover, the methylation level of LRRC26 was also significantly reduced in HCC1937 cells following treatment with 5'-aza-dC (Fig. 2B).

Subsequently, RNA-seq analysis of 919 breast cancer cases from TCGA dataset revealed that $L R R C 26$ gene expression in TNBC cases was significantly lower than that in other subtypes, such as ER(+)/HER2(-), ER(土)/HER2(+) (Fig. 2C), whereas LRRC26 gene methylation analysis of 625 cases on the same dataset was significantly higher in TNBC cases than in other subtypes (Fig. 2D). Furthermore, bisulfite pyrosequencing analysis was performed using a set of 12 TNBC clinical tissues and adjacent normal breast tissues to analyze the methylation level of $L R R C 26$ at seqTCGA located $373 \mathrm{bp}$ upstream of the transcriptional start site (Fig. 2E). The results showed that the methylation level of the seqTCGA CpG island was significantly higher in all tumor tissues than that in the adjacent normal mammary gland tissues (Wilcoxon signed-rank test: $\mathrm{P}=0.002$ ) (Fig. 2E). These data strongly suggested that low LRRC26 expression due to hypermethylation in its promoter region is exclusive to TNBC cases.

LRRC26 as a tumor suppressor in TNBC cells. To investigate the impact of $L R R C 26$ on cell growth in HCC70 TNBC cells, standard cell proliferation assays were performed. First, the knockdown of LRRC26 expression was confirmed in HCC70 cells, in which $L R R C 26$ was highly expressed, as determined by qPCR (Fig. 3A), and it was found that LRRC26 silencing did not affect cell proliferation (Fig. 3A), consistent with the findings of a previous study using LNCaP prostate cancer cells (18). Next, to further assess the tumor suppressive function of $L R R C 26$ on the development and progression of TNBC cells, soft agar colony formation, invasion and migration assays were performed to evaluate metastatic properties. Knocking down LRRC26 expression significantly increased the number of colonies in the soft agar (Fig. 3B), suggesting a critical role for $L R R C 26$ in anchorage-independent growth. Subsequent Matrigel invasion and migration assays also revealed that siRNA-mediated depletion of $L R R C 26$ expression led to significant facilitation of HCC70 cell invasion and migration compared with that in siEGFP-transfected cells (Fig. 3C and D). Furthermore, the effects of LRRC26 overexpression on migration, invasion and cell proliferation in BT-20 cells, which express $L R R C 26$ at a low level, were examined. The results showed that LRRC26 overexpression led to a reduction in the migration and invasion and abilities (Fig. 3F and G) of the cells, but did not effect cell viability (Fig. 3H). Taken together, these findings strongly suggest that LRRC26 suppresses the aggressive behavior of TNBC cells.

LRRC26 expression negatively regulates the TNF- $\alpha$-induced $N F-\kappa B$ pathway. LRRC26 has been reported to negatively regulate $\mathrm{NF}-\kappa \mathrm{B}$ signaling in prostate cancer LNCaP cells (18). Therefore, the effect of $L R R C 26$ on $\mathrm{NF}-\kappa \mathrm{B}$ activity was examined in the present study using a luciferase reporter assay and qPCR analysis. A significant time-dependent decrease in luciferase activity was observed in the presence of TNF- $\alpha$ stimulation with ectopic LRRC26 expression compared with that in the mock control vector in 293T cells (Fig. 4A). qPCR analysis showed that siRNA-mediated $L R R C 26$-knockdown significantly increased the TNF- $\alpha$-induced expression of the NF- $\mathrm{BB}$ target genes $I L-6, I L-8$ and $C X C L 1$ in HCC70 cells (Fig. 4B). These results suggested that LRRC26 negatively regulates $\mathrm{TNF}-\alpha$-induced $\mathrm{NF}-\kappa \mathrm{B}$ activity.

Functional gene annotation clustering analysis. To further clarify the biological role of LRRC26 in the progression or development of TNBC cells, the present study attempted to identify the processes or pathways associated with LRRC26 in TNBC cells. siLRRC26, or siEGFP as a control, was transfected into HCC70 cells, which highly express $L R R C 26$, and alterations in gene expression were measured using DNA microarray analysis. To identify genes associated with $L R R C 26$, genes were selected using the following criterion: Expression level was decreased or increased by $>3$-fold in siLRRC26-transfected cells compared with that in siEGFP-transfected cells. This approach identified 230 genes that were altered upon LRRC26-knockdown (Table V). Among them, the downregulation of olfactory receptor family 5 subfamily M member 1 (OR5MI) and OR5T1 genes, which encode members of olfactory GPCR protein, was verified in LRRC26-depleted cells, as determined by qPCR (Fig. 5A). Notably, OR5T1 protein is predicted to be N-glycosylated at Asn17, suggesting the possibility that LRRC26 downregulation may be important for ORT51 glycosylation. To further identify significantly overrepresented Gene Ontology terms affected by LRRC26 expression in HCC70 cells, these upregulated or downregulated genes were analyzed using the DAVID algorithm (27,31). The most prominent cluster (annotation cluster 1; gene enrichment score, 3.12) was identified, which contained features related to 'glycoprotein', 'signal peptide', 'secreted' and 'N-linked glycoprotein (GlcNAc)' (Table VI). Furthermore, the immunocytochemical staining experiments showed that exogenous HA-LRRC26 was found to be partially co-localized with endogenous GRP78, a molecular chaperone localized in the endoplasmic reticulum (Fig. 5B), and exogenous FLAG-tagged BAP31, an integral membrane protein of the endoplasmic reticulum, in BT20 cells (Fig. 5C), indicating the possibility that LRRC26 may function in the endoplasmic reticulum of TNBC cells. These findings suggested the possibility that $L R R C 26$ downregulation may affect the secretory pathway from the Golgi apparatus to the cell surface or vesicle transport from the endoplasmic reticulum to the Golgi apparatus in TNBC cells.

\section{Discussion}

Genetic and epigenetic inactivation involving DNA methylation and histone modifications of tumor suppressor genes serve a crucial role in the progression and development of breast cancer $(20,32)$. Notably, aberrant promoter hypermethylation of tumor suppressor genes is commonly observed in breast cancer and is the predominant mechanism for loss of function. In the present study, it was demonstrated that LRRC26 downregulation contributes to the progression and development of TNBC, although further analysis of understanding of the mechanism of LRRC26 upregulation in breast cancer, particularly ER- and HER2-positive breast cancer, will be necessary. 

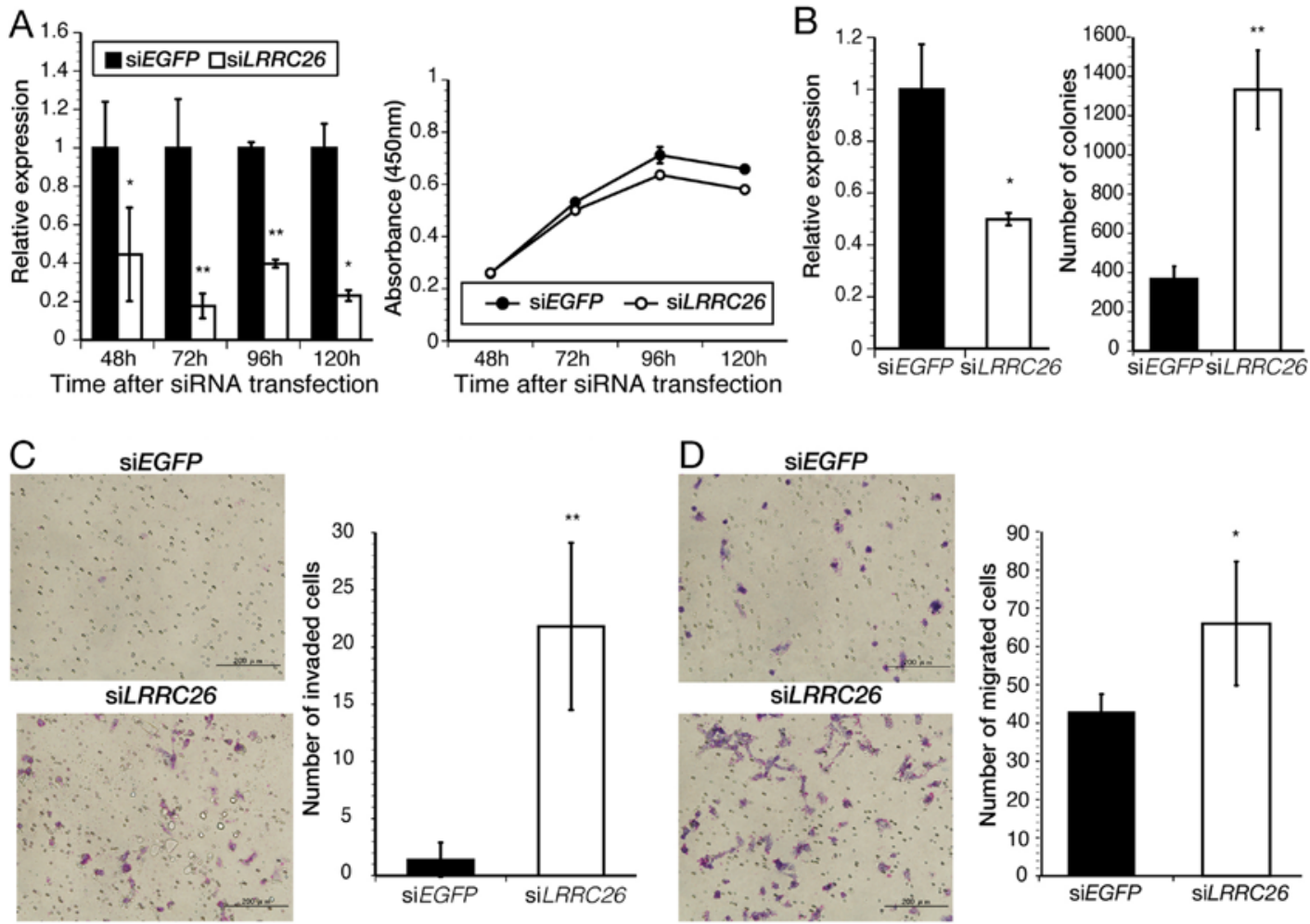

$\mathrm{E}$
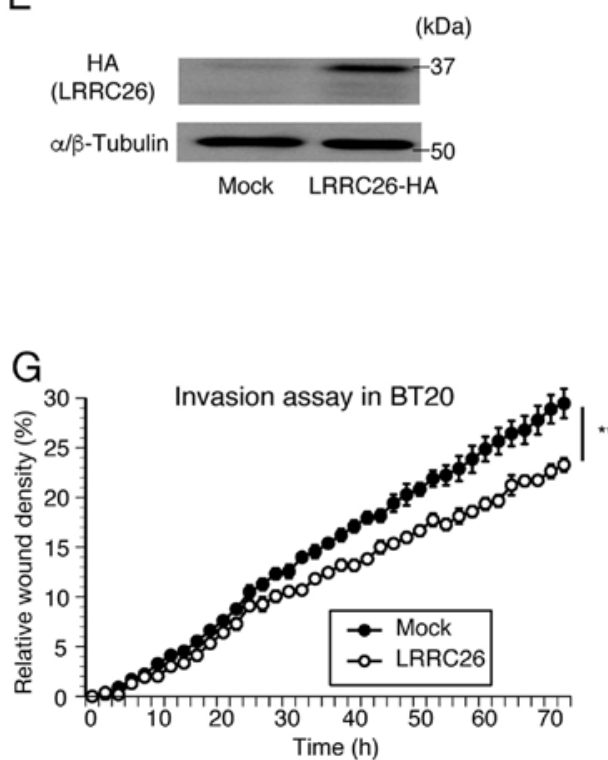

$\mathrm{F}$
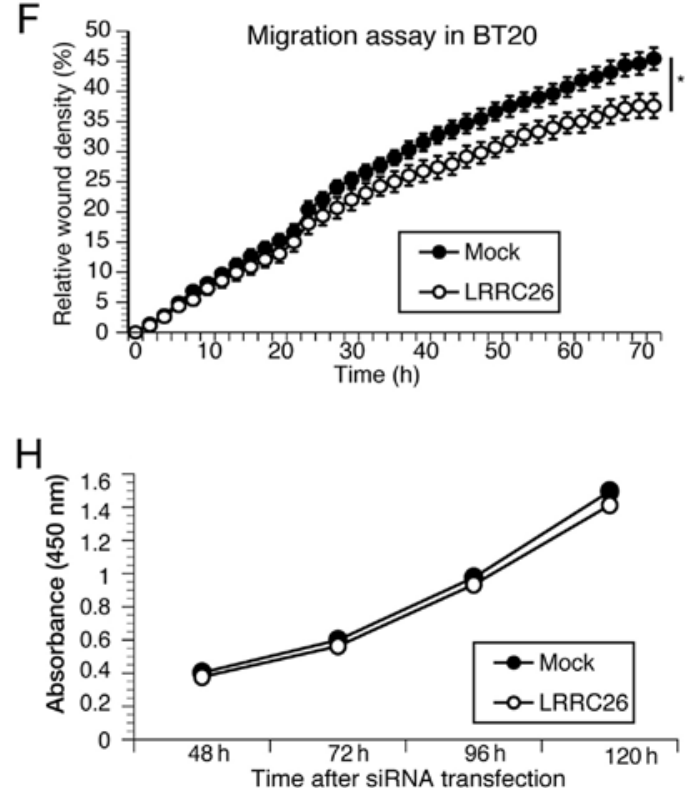

Figure 3. Functional analysis of LRRC26 in HCC70 triple-negative breast cancer cells. (A) qPCR analysis of LRRC26 in HCC70 cells transfected with siLRRC26 (ON-TARGETplus siRNA) and siEGFP as a control for 48, 72, 96 and $120 \mathrm{~h}$ (left panel). (A) Cell proliferation assay was performed to evaluate the growth suppressing effect of $L R R C 26$ in HCC70 cells (right panel). (B) Soft agar colony formation assays were performed for $36 \mathrm{~h}$ to evaluate anchorage-independent growth of LRRC26 in HCC70 cells (right panel) 11 days after siLRRC26 treatment. qPCR analysis was performed for $L R R C 26$ in HCC70 cells transfected with siLRRC26 (ON-TARGETplus siRNA) and siEGFP as a control for $36 \mathrm{~h}$ (left panel). (C) Cell invasion assay with HCC70 using BD Falcon Cell Culture Inserts at $48 \mathrm{~h}$ after siLRRC26 treatment for $36 \mathrm{~h}$. Representative images of invasion assays are shown (left panel). (D) Cell migration assay with HCC70 using Corning Matrigel Invasion Chambers at $48 \mathrm{~h}$ after siLRRC26 treatment for $36 \mathrm{~h}$. Representative images of migration assays are shown (left panel). The data represent the mean \pm standard deviation of each condition ("P $<0.05$ and ${ }^{* *} \mathrm{P}<0.01$; two-sided Student's $\mathrm{t}$-test). (E) Immunoblotting analysis of LRRC26-HA expression in BT20 cells transfected with LRRC26-HA and an empty vector (Mock) as a control for $48 \mathrm{~h}$. (F) Cell migration of BT20 cells transfected with LRRC26-HA or an empty vector (Mock) were measured using the Incucyte for $72 \mathrm{~h}$ after $48 \mathrm{~h}$ of transfection. (G) Cell invasion of BT20 cells transfected with LRRC26-HA or an empty vector (Mock) were measured using Incucyte for $72 \mathrm{~h}$ after $48 \mathrm{~h}$ of transfection. (H) An MTT assay was performed to evaluate the growth suppressing effect of $L R R C 26$ overexpression in BT20 cells. LRRC26, leucine-rich repeat-containing 26; siEGFP, small interfering enhanced green fluorescent protein; qPCR, quantitative polymerase chain reaction.

Although RNA-seq and public TCGA database analyses identified no somatic mutations of the LRRC26 mRNA in the
TNBC tissues and cell lines, the frequent downregulation of LRRC26 due to promoter hypermethylation at Seq.1 and Seq.2 

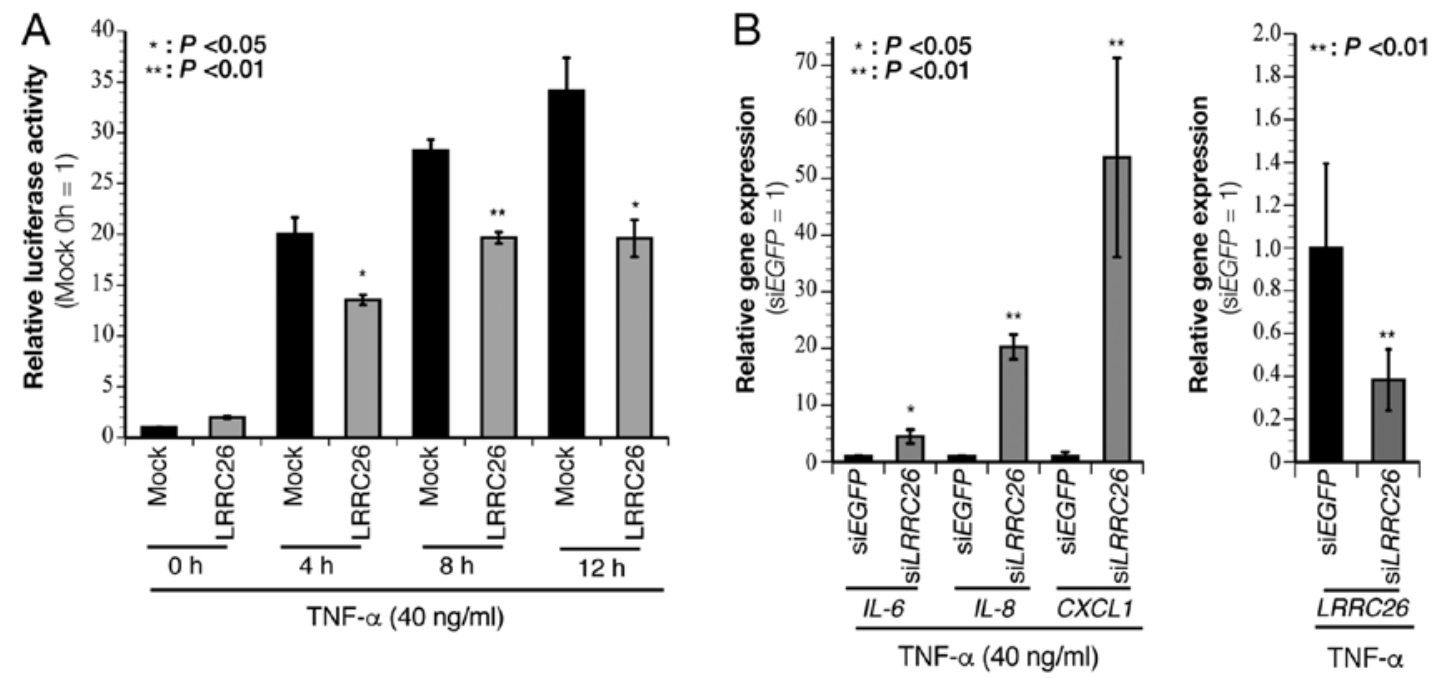

Figure 4. LRRC26 negatively regulates the NF-кB pathway. (A) Luciferase assay using lysates of 293T cells co-transfected with a luciferase reporter plasmid for NF- $\mathrm{kB}$ and a LRRC26 gene plasmid following stimulation with TNF- $\alpha(40 \mathrm{ng} / \mathrm{ml})$ for $0,4,8$ and $12 \mathrm{~h}$, respectively. (B) Quantitative polymerase chain reaction analysis to evaluate the expression of NF- $\mathrm{KB}$-target genes, including $I L-6, I L-8$ and $C X C L 1$, following TNF- $\alpha$ ( $40 \mathrm{ng} / \mathrm{ml})$ stimulation in siLRRC26-transfected HCC70 cells. The data represent the mean \pm standard deviation of each condition $\left(\mathrm{n}=3\right.$, ${ }^{*} \mathrm{P}<0.05$ and ${ }^{* *} \mathrm{P}<0.01$; two-sided Student's t-test). LRRC26, leucine-rich repeat-containing 26; EGFP, enhanced green fluorescent protein; NF- $\mathrm{kB}$, nuclear factor- $\mathrm{\kappa B}$; si, small interfering; IL, interleukin; CXCL1, C-X-C motif chemokine ligand-1; TNF- $\alpha$, tumor necrosis factor- $\alpha$.

in TNBC tissues and cell lines was observed (Fig. 1B-E). Notably, LRRC26 was highly expressed in HCC70 cells, but not in MDA-MB-231 cells, whereas LRRC26 methylation levels at the two $\mathrm{CpG}$ sites were similar between $\mathrm{HCC} 70$ and MDA-MB-231 cells (Fig. 1D and E). This discrepancy implies the existence of other critical CpG sites in the LRRC26 promoter region that may be responsible for gene silencing. In fact, the methylation level of the seqTCGA CpG island, located $373 \mathrm{bp}$ upstream of the transcriptional start site, was significantly higher in all tumor tissues compared with that in adjacent normal mammary gland tissues (Fig. 2E). By contrast, LRRC26 was also not methylated in other $\mathrm{CpG}$ islands within $200 \mathrm{bp}$ of the transcription initiation site, particularly around the transcription initiation site of the LRRC26 gene in HCC70 cells. Notably, miRDB, an online database for miRNA target prediction (33), predicted LRRC26 as a target of hsa-miR-1275. hsa-miR-1275 is reported to be upregulated in young women ( $<35$ years old) with breast cancer compared with that in older women ( $>65$ and 45-65 years old) (34), as well as in MDA-MB-231 TNBC cells (35), suggesting the possibility that epigenetic and miRNA-mediated inactivation may contribute to $L R R C 26$ downregulation.

By analyzing TCGA RNA-seq public databases in the present study, it was found that $L R R C 26$ gene expression was significantly lower in TNBC cases than in ER-positive/HER2-negative and ER-negative/HER2-positive breast cancer cases (Fig. 2C and D), suggesting that hypermethylation-mediated $L R R C 26$ inactivation may be a TNBC-specific event in the progression and development of cancer cells. Further statistical analysis demonstrated that LRRC26 downregulation was significantly associated with increased histological grade in patients with TNBC $(\mathrm{P}=0.017$; $\chi^{2}$ test) (Table IV), whereas Kaplan-Meier analysis revealed no significant association between LRRC26 downregulation and the overall survival of patients with TNBC (data not shown). These findings suggested that LRRC26 downregu- lation may be involved in the aggressiveness of TNBC, but that in addition to $L R R C 26$ downregulation, other factors may also be necessary to drive malignacy. Further analysis of the association between LRRC26 downregulation and prognosis using a large number of TNBC samples will also be necessary. Furthermore, LRRC26 has been reported to suppress tumor growth by negatively regulating NF- $\mathrm{KB}$ signaling in LNCaP and MDA-MB-231 cells (18). However, in the present study, the upregulation of NF- $\mathrm{kB}$-target genes in the absence of TNF- $\alpha$ stimulation was not observed in LRRC26-depleted HCC70 cells (data not shown), although the upregulation of NF- $\mathrm{kB}$-target genes in the presence of TNF- $\alpha$ stimulation was observed in these cells (Fig. 4B). These results suggest that $L R R C 26$ downregulation may be important for TNF- $\alpha$-mediated NF- $\kappa$ B activation in TNBC cells. Furthermore, LRRC26 expression has been reported to promote anchorage-independent growth in MDA-MB231 cells (18). The present study also found that knocking down LRRC26 increased not only anchorage-independent growth, but also invasion and migration in HCC70 cells; however, it did not promote proliferation in the absence of TNF- $\alpha$ stimulation, suggesting that $L R R C 26$ downregulation is critical for the TNF- $\alpha$-mediated NF- $\kappa B$-independent progression of TNBC.

To investigate biological roles of $L R R C 26$ distinct from the NF- $\mathrm{KB}$ pathway in TNBC cells, DNA microarray analysis was performed using siLRRC26-transfected HCC70 cells. Functional annotation clustering revealed that upregulated and downregulated genes in LRRC26-depleted HCC70 cells are functionally associated with protein secretion and $\mathrm{N}$-linked glycosylation. These findings suggest the possibility that LRRC26 downregulation may affect the secretory pathway from the Golgi apparatus to the cell surface or vesicle transport from the endoplasmic reticulum to the Golgi apparatus.

LRRC26 protein, a member of the LRR superfamily, has been reported to act as a big potassium (BK) channel auxiliary subunit, whereas the regulation of NF- $\kappa \mathrm{B}$ activation 
A
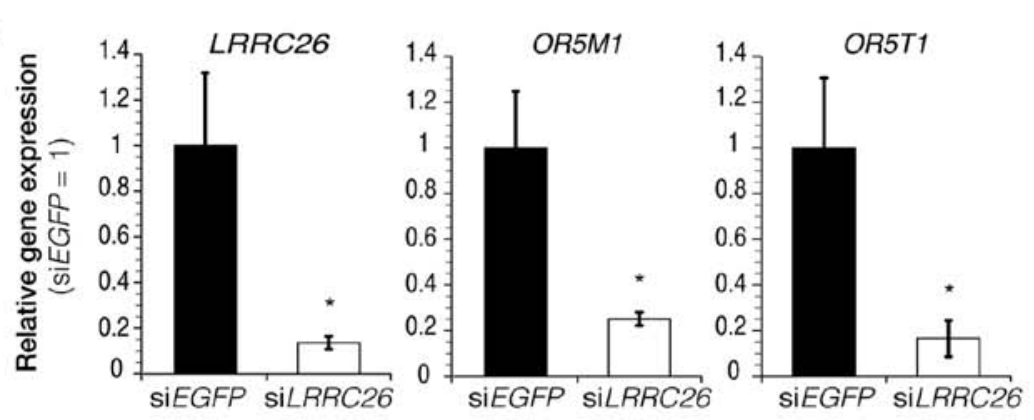

$\mathrm{B}$
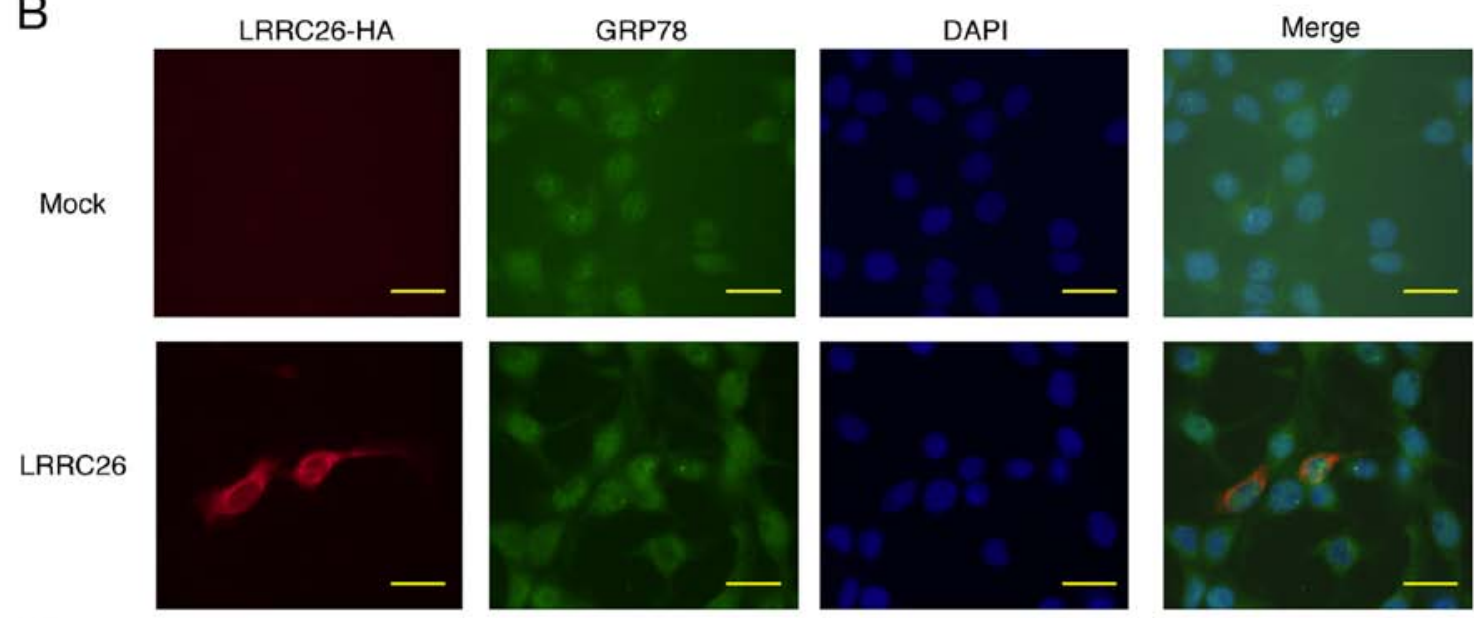

C

LRRC26-HA
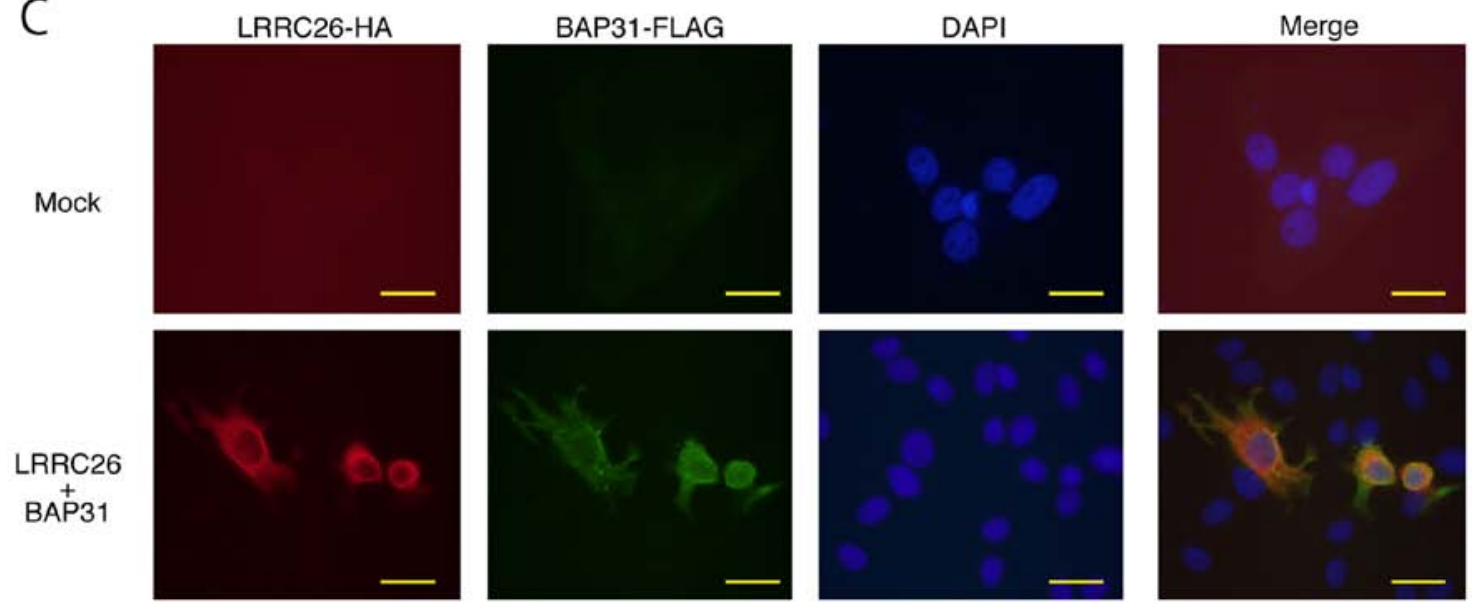

Figure 5. LRRC26 potentially functions in the endoplasmic reticulum in TNBC cells. (A) Verification of downregulation of OR5M1 and OR5T1 in LRRC26-depleted cells by quantitative polymerase chain reaction. (B) Exogenous LRRC26-HA was partially merged with endogenous GRP78 in the endoplasmic reticulum of BT20 cells, and immunostained with anti-HA (red) or anti-GRP78 (green) antibodies, and DAPI (blue) to discriminate the nucleus. (C) Co-localization of exogenous LRRC26-HA and BAP31-FLAG in the endoplasmic reticulum of BT20 cells, and immunostained with anti-HA (red) or anti-FLAG (green) antibodies, and DAPI (blue) to discriminate the nucleus. LRRC26, leucine-rich repeat-containing 26; OR5M1, olfactory receptor family 5 subfamily M member 1; si, small interfering; EGFP, enhanced green fluorescent protein; BAP31, B cell receptor associated protein 31.

by LRRC26 is independent of BK channels (36). Notably, LRRC26 is also predicted to be present on the endoplasmic reticulum membrane via its $\mathrm{N}$-terminal LRR domain, as LRRC26 is N-glycosylated at an Asn147 site in the endoplasmic reticulum (36). LRRC26 has been reported to localize in the endoplasmic reticulum (36). In fact, the present study demonstrated that LRRC26 was observed to be co-localized with GRP78 and BAP31 in the endoplasmic reticulum of TNBC cells (Fig. 5B and C). Moreover, N-linked glycoproteins are composed of a polypeptide glycosylated in the endoplasmic reticulum with several carbonate chains via asparagine residues, and have critical roles in cell-cell interaction and cell adhesion for invasive and metastatic behaviors in breast cancer. These results strongly suggest that $L R R C 26$ may serve a role in breast cancer progression (37-40). However, further analyses are required to elucidate the effects of $L R R C 26$ downregulation on N-linked glycosylation in TNBC cells.

In summary, the present study demonstrated that the methylation-mediated inactivation of LRRC26 resulted in enhancement of anchorage-independent growth-, invasion- and migration-associated metastatic behavior. Notably, frequent methylation-mediated inactivation of LRRC26 is a TNBC-specific event that may be a potential diagnostic biomarker. 
Table V. Genes that were altered upon leucine-rich repeat-containing 26-knockdown according to DNA microarray analysis $(n=230)$.

\begin{tabular}{|c|c|c|}
\hline Gene symbol & Gene name & Fold-chan \\
\hline \multicolumn{3}{|l|}{ Upregulation } \\
\hline$A N K R D 30 A$ & Ankyrin repeat domain $30 \mathrm{~A}$ & 30.29 \\
\hline$M E P E$ & Matrix extracellular phosphoglycoprotein & 26.45 \\
\hline$D A C T 1$ & Dishevelled-binding antagonist of $\beta$-catenin 1 & 24.11 \\
\hline$M G A T 5 B$ & Mannosyl ( $\alpha$-1,6-)-glycoprotein $\beta$-1,6-N-acetyl-glucosaminyltransferase, isozyme B & 17.55 \\
\hline PLCB4 & Phospholipase $\mathrm{C}, \beta 4$ & 17.10 \\
\hline NME8 & NME/NM23 family member 8 & 14.79 \\
\hline$H M C N 2$ & Hemicentin 2 & 13.61 \\
\hline$S L C 2 A 7$ & Solute carrier family 2 (facilitated glucose transporter), member 7 & 13.57 \\
\hline TSPAN11 & Tetraspanin 11 & 11.90 \\
\hline$A C T G 2$ & Actin, gamma 2 , smooth muscle, enteric & 11.76 \\
\hline CCL11 & Chemokine (C-C motif) ligand 11 & 11.26 \\
\hline GCNT3 & Glucosaminyl (N-acetyl) transferase 3 , mucin type & 10.82 \\
\hline$C C D C 162 P$ & Coiled-coil domain containing 162, pseudogene & 9.65 \\
\hline EWSAT1 & Ewing sarcoma associated transcript 1 & 9.18 \\
\hline$D P E P 1$ & Dipeptidase 1 (renal) & 9.01 \\
\hline$C A M P$ & Cathelicidin antimicrobial peptide & 8.96 \\
\hline$P P P 1 R 42$ & Protein phosphatase 1 , regulatory subunit 42 & 8.01 \\
\hline COL24Al & Collagen, type XXIV, $\alpha 1$ & 7.82 \\
\hline$S C N 5 A$ & Sodium channel, voltage gated, type $V \alpha$ subunit & 7.50 \\
\hline TMEM236 & Transmembrane protein 236 & 7.46 \\
\hline ELF5 & E74-like factor 5 (ets domain transcription factor) & 7.23 \\
\hline ITIH5 & Inter- $\alpha$-trypsin inhibitor heavy chain family, member 5 & 6.97 \\
\hline NAT2 & $\mathrm{N}$-acetyltransferase 2 (arylamine $\mathrm{N}$-acetyltransferase) & 6.73 \\
\hline DOCK2 & Dedicator of cytokinesis 2 & 6.45 \\
\hline CFAP61 & Cilia and flagella-associated protein 61 & 6.10 \\
\hline TRPAl & Transient receptor potential cation channel, subfamily A, member 1 & 6.07 \\
\hline$A Z U 1$ & Azurocidin 1 & 5.84 \\
\hline$C L N K$ & Cytokine-dependent hematopoietic cell linker & 5.83 \\
\hline MORN3 & MORN repeat containing 3 & 5.58 \\
\hline ARSE & Arylsulfatase E (chondrodysplasia punctata 1) & 5.46 \\
\hline FENDRR & FOXF1 adjacent non-coding developmental regulatory RNA & 5.27 \\
\hline IZUMO4 & IZUMO family member 4 & 5.09 \\
\hline PHOX $2 B$ & Paired-like homeobox $2 b$ & 4.99 \\
\hline DKFZP434L187 & Uncharacterized LOC26082 & 4.90 \\
\hline WHAMMP3 & $\begin{array}{l}\text { WAS protein homolog associated with actin, } \\
\text { golgi membranes and microtubules pseudogene } 3\end{array}$ & 4.84 \\
\hline РНYНIP & Phytanoyl-CoA 2-hydroxylase interacting protein & 4.81 \\
\hline GRIK2 & Glutamate receptor, ionotropic, kainate 2 & 4.68 \\
\hline CNOT2 & CCR4-NOT transcription complex, subunit 2 & 4.59 \\
\hline$C C D C 162 P$ & Coiled-coil domain containing 162 , pseudogene & 4.53 \\
\hline TMEM236 & Transmembrane protein 236 & 4.50 \\
\hline MEGF11 & Multiple EGF-like-domains 11 & 4.44 \\
\hline TMEM35 & Transmembrane protein 35 & 4.39 \\
\hline LDLRAD1 & Low density lipoprotein receptor class A domain-containing 1 & 4.38 \\
\hline FRMD3 & FERM domain containing 3 & 4.34 \\
\hline$F G G$ & Fibrinogen $\gamma$ chain & 4.29 \\
\hline GP6 & Glycoprotein VI (platelet) & 4.28 \\
\hline C7orf69 & Chromosome 7 open reading frame 69 & 4.21 \\
\hline$R N F 17$ & Ring finger protein 17 & 4.20 \\
\hline PECAMI & Platelet/endothelial cell adhesion molecule 1 & 4.19 \\
\hline
\end{tabular}


Table V. Continued.

\begin{tabular}{|c|c|c|}
\hline Gene symbol & Gene name & Fold-chang \\
\hline$G R I K 2$ & Glutamate receptor, ionotropic, kainate 2 & 4.16 \\
\hline ORIOV1 & Olfactory receptor, family 10 , subfamily $\mathrm{V}$, member 1 & 4.11 \\
\hline$A S P D H$ & Aspartate dehydrogenase domain containing & 4.02 \\
\hline$B C A S 1$ & Breast carcinoma amplified sequence 1 & 3.99 \\
\hline$A N K R D 22$ & Ankyrin repeat domain 22 & 3.97 \\
\hline$A L K B H 3-A S 1$ & ALKBH3 antisense RNA 1 & 3.96 \\
\hline TMEM215 & Transmembrane protein 215 & 3.92 \\
\hline$C D S N$ & Corneodesmosin & 3.82 \\
\hline PRR30 & Proline rich 30 & 3.75 \\
\hline$C C D C 8$ & Coiled-coil domain-containing 8 & 3.75 \\
\hline$G R A M D 1 B$ & GRAM domain-containing 1B & 3.70 \\
\hline$A N K R D 20 A 12 P$ & Ankyrin repeat domain 20 family, member A12, pseudogene & 3.68 \\
\hline OR5D18 & Olfactory receptor, family 5, subfamily D, member 18 & 3.59 \\
\hline FAM209B & Family with sequence similarity 209, member B & 3.57 \\
\hline$C L E C 1 B$ & C-type lectin domain family 1, member B & 3.55 \\
\hline USP $17 L 8$ & Ubiquitin specific peptidase 17 -like family member 8 & 3.54 \\
\hline$B M F$ & Bcl-2 modifying factor & 3.52 \\
\hline$Z F H X 2$ & Zinc finger homeobox 2 & 3.52 \\
\hline$R B P M S$ & RNA binding protein with multiple splicing & 3.51 \\
\hline TTC29 & Tetratricopeptide repeat domain 29 & 3.49 \\
\hline PCDH11Y & Protocadherin 11 Y-linked & 3.48 \\
\hline$E F H B$ & EF-hand domain family, member B & 3.44 \\
\hline NBAT1 & Neuroblastoma-associated transcript 1 & 3.41 \\
\hline$H E M G N$ & Hemogen & 3.41 \\
\hline$W N T 3 A$ & Wingless-type MMTV integration site family, member 3A & 3.32 \\
\hline$P A R D 6 G$ & Par-6 family cell polarity regulator $\gamma$ & 3.31 \\
\hline KCTD8 & Potassium channel tetramerization domain-containing 8 & 3.30 \\
\hline$M G C 27382$ & Uncharacterized MGC27382 & 3.28 \\
\hline Р4HA3 & Prolyl 4-hydroxylase, $\alpha$ polypeptide III & 3.21 \\
\hline SMIM9 & Small integral membrane protein 9 & 3.19 \\
\hline PTPRC & Protein tyrosine phosphatase, receptor type, $\mathrm{C}$ & 3.16 \\
\hline$K L B$ & Klotho $\beta$ & 3.13 \\
\hline CLDN19 & Claudin 19 & 3.13 \\
\hline$M G C 27382$ & Uncharacterized MGC27382 & 3.13 \\
\hline$Z P 1$ & Zona pellucida glycoprotein 1 (sperm receptor) & 3.13 \\
\hline PTPRC & Protein tyrosine phosphatase, receptor type, C & 3.12 \\
\hline C15orf32 & Chromosome 15 open reading frame 32 & 3.11 \\
\hline NLRP12 & NLR family, pyrin domain containing 12 & 3.11 \\
\hline POLH & Polymerase (DNA directed), $\eta$ & 3.08 \\
\hline KIAA1731NL & KIAA1731 N-terminal like & 3.06 \\
\hline PRPS1 & Phosphoribosyl pyrophosphate synthetase 1 & 3.05 \\
\hline \multicolumn{3}{|l|}{ Downregulation } \\
\hline$D C A F 12 L 1$ & DDB1 and CUL4 associated factor 12-like 1 & -31.73 \\
\hline$R E G 3 A$ & Regenerating islet-derived $3 \alpha$ & -29.34 \\
\hline CXorf 21 & Chromosome $\mathrm{X}$ open reading frame 21 & -23.23 \\
\hline$T A T$ & Tyrosine aminotransferase & -22.82 \\
\hline MS4A12 & Membrane-spanning 4-domains, subfamily A, member 12 & -22.56 \\
\hline OR5M1 & Olfactory receptor, family 5 , subfamily $\mathrm{M}$, member 1 & -20.76 \\
\hline C10orf90 & Chromosome 10 open reading frame 90 & -19.70 \\
\hline ADAM5 & ADAM metallopeptidase domain 5 (pseudogene) & -18.73 \\
\hline$H N R N P K P 3$ & Heterogeneous nuclear ribonucleoprotein K pseudogene 3 & -17.57 \\
\hline$B M P 7$ & Bone morphogenetic protein 7 & -17.32 \\
\hline
\end{tabular}


Table V. Continued.

\begin{tabular}{|c|c|c|}
\hline Gene symbol & Gene name & Fold-chang \\
\hline OR5T1 & Olfactory receptor, family 5 , subfamily $\mathrm{T}$, member 1 & -16.91 \\
\hline$A Q P 10$ & Aquaporin 10 & -16.63 \\
\hline NBAT1 & Neuroblastoma associated transcript 1 & -16.43 \\
\hline ORIA1 & Olfactory receptor, family 1 , subfamily A, member 1 & -16.24 \\
\hline$C A L Y$ & Calcyon neuron-specific vesicular protein & -15.47 \\
\hline$M A P 3 K 13$ & Mitogen-activated protein kinase kinase kinase 13 & -14.49 \\
\hline NCRNA00249 & Uncharacterized LOC101926947 & -13.95 \\
\hline$S L C 22 A 11$ & Solute carrier family 22 (organic anion/urate transporter), member 11 & -13.81 \\
\hline SNORD116-11 & Small nucleolar RNA, C/D box 116-11 & -13.67 \\
\hline LILRB 4 & $\begin{array}{l}\text { Leukocyte immunoglobulin-like receptor, subfamily B } \\
\text { (with TM and ITIM domains), member } 4\end{array}$ & -13.62 \\
\hline$E R V V-2$ & Endogenous retrovirus group $\mathrm{V}$, member 2 & -13.31 \\
\hline TTC24 & Tetratricopeptide repeat domain 24 & -12.83 \\
\hline PCDHB15 & Protocadherin $\beta 15$ & -11.64 \\
\hline ZNF705G & Zinc finger protein $705 \mathrm{G}$ & -10.80 \\
\hline FAM20A & Family with sequence similarity 20 , member A & -10.79 \\
\hline LILRA3 & Leukocyte immunoglobulin-like receptor, subfamily A (without TM domain), member 3 & -10.65 \\
\hline PALM2 & Paralemmin 2 & -10.33 \\
\hline RSPH6A & Radial spoke head 6 homolog A (Chlamydomonas) & -10.25 \\
\hline ANGPTL1 & Angiopoietin-like 1 & -10.14 \\
\hline ATP8B2 & ATPase, aminophospholipid transporter, class I, type 8B, member 2 & -10.07 \\
\hline FMO9P & Flavin containing monooxygenase 9 pseudogene & -9.60 \\
\hline MEIS1-AS2 & MEIS1 antisense RNA 2 & -9.47 \\
\hline$P K D C C$ & Protein kinase domain containing, cytoplasmic & -9.20 \\
\hline$R B M Y 1 B$ & RNA binding motif protein, Y-linked, family 1 , member B & -9.19 \\
\hline CFAP46 & Cilia and flagella-associated protein 46 & -9.06 \\
\hline BIRC8 & Baculoviral IAP repeat-containing 8 & -8.96 \\
\hline PENK & Proenkephalin & -8.95 \\
\hline C9orf47 & Chromosome 9 open reading frame 47 & -8.73 \\
\hline PRDM16 & PR domain containing 16 & -8.70 \\
\hline FAM104B & Family with sequence similarity 104 , member B & -8.54 \\
\hline NLRP4 & NLR family, pyrin domain containing 4 & -8.51 \\
\hline MOV1OL1 & Mov10 RISC complex RNA helicase like 1 & -8.30 \\
\hline SLAMF8 & SLAM family member 8 & -8.28 \\
\hline C7orf71 & Chromosome 7 open reading frame 71 & -8.18 \\
\hline SOGA3 & SOGA family member 3 & -8.16 \\
\hline$S L C 2 A 1-A S 1$ & SLC2A1 antisense RNA 1 & -8.15 \\
\hline$T X N D C 8$ & Thioredoxin domain-containing 8 (spermatozoa) & -7.80 \\
\hline PCLO & Piccolo presynaptic cytomatrix protein & -7.75 \\
\hline$R N F 17$ & Ring finger protein 17 & -7.69 \\
\hline$A C A D L$ & Acyl-CoA dehydrogenase, long chain & -7.46 \\
\hline GPR123 & G protein-coupled receptor 123 & -7.41 \\
\hline RPS6KA2-AS1 & RPS6KA2 antisense RNA 1 & -7.26 \\
\hline LRRC34 & Leucine rich repeat containing 34 & -7.21 \\
\hline TMEM98 & Transmembrane protein 98 & -7.18 \\
\hline$D A C T 2$ & Dishevelled-binding antagonist of $\beta$-catenin 2 & -6.94 \\
\hline C20orf173 & Chromosome 20 open reading frame 173 & -6.85 \\
\hline$T B X 18$ & T-box 18 & -6.64 \\
\hline ANKRD62 & Ankyrin repeat domain 62 & -6.43 \\
\hline$V A X 1$ & Ventral anterior homeobox 1 & -6.15 \\
\hline$P I P 5 K 1 B$ & Phosphatidylinositol-4-phosphate 5-kinase, type I, $\beta$ & -6.07 \\
\hline$M Z B 1$ & Marginal zone B and B1 cell-specific protein & -6.04 \\
\hline
\end{tabular}


Table V. Continued.

\begin{tabular}{|c|c|c|}
\hline Gene symbol & Gene name & Fold-chang \\
\hline$M I R 3663 H G$ & miR3663 host gene (non-protein coding) & -6.03 \\
\hline$D E F B 133$ & Defensin, $\beta 133$ & -5.99 \\
\hline$M M P 13$ & Matrix metallopeptidase 13 (collagenase 3 ) & -5.94 \\
\hline ZFYVE28 & Zinc finger, FYVE domain containing 28 & -5.82 \\
\hline DUX3 & Double homeobox 3 & -5.81 \\
\hline IFNL3 & Interferon $\lambda 3$ & -5.80 \\
\hline$M T 1 D P$ & Metallothionein 1D, pseudogene (functional) & -5.61 \\
\hline TP53AIP1 & Tumor protein p53 regulated apoptosis inducing protein 1 & -5.50 \\
\hline KCNMAl & Potassium channel, calcium activated large conductance subfamily $\mathrm{M} \alpha$, member 1 & -5.47 \\
\hline MRPL23-AS1 & MRPL23 antisense RNA 1 & -5.41 \\
\hline PCSK1 & Proprotein convertase subtilisin/kexin type 1 & -5.37 \\
\hline$I P W$ & Imprinted in Prader-Willi syndrome (non-protein coding) & -5.24 \\
\hline$U P K 1 A$ & Uroplakin $1 \mathrm{~A}$ & -5.09 \\
\hline NAIP & NLR family, apoptosis inhibitory protein & -4.84 \\
\hline$A B I 3 B P$ & ABI family, member 3 (NESH) binding protein & -4.79 \\
\hline ENDOV & Endonuclease V & -4.66 \\
\hline$M A P 2$ & Microtubule-associated protein 2 & -4.66 \\
\hline HMBOX1 & Homeobox containing 1 & -4.65 \\
\hline CHIAP2 & Chitinase, acidic pseudogene 2 & -4.60 \\
\hline BMS1P17 & BMS1 pseudogene 17 & -4.52 \\
\hline SPOCK3 & Sparc/osteonectin, cwcv and kazal-like domains proteoglycan (testican) 3 & -4.51 \\
\hline$R A S S F 3$ & Ras association (RalGDS/AF-6) domain family member 3 & -4.51 \\
\hline$S L C 24 A 1$ & Solute carrier family 24 (sodium/potassium/calcium exchanger), member 1 & -4.47 \\
\hline $\mathrm{NR} 1 \mathrm{H} 2$ & Nuclear receptor subfamily 1 , group $\mathrm{H}$, member 2 & -4.46 \\
\hline$R B M Y 1 B$ & RNA binding motif protein, Y-linked, family 1, member B & -4.42 \\
\hline BPIFB4 & BPI fold containing family $\mathrm{B}$, member 4 & -4.39 \\
\hline$R A G 2$ & Recombination activating gene 2 & -4.34 \\
\hline$R B M X L 2$ & RNA binding motif protein, X-linked-like 2 & -4.26 \\
\hline$M A S P 1$ & Mannan-binding lectin serine peptidase 1 (C4/C2 activating component of Ra-reactive factor) & -4.25 \\
\hline AIPL1 & Aryl hydrocarbon receptor interacting protein-like 1 & -4.16 \\
\hline$S G P P 2$ & Sphingosine-1-phosphate phosphatase 2 & -4.13 \\
\hline PLGLB 1 & Plasminogen-like B1 & -4.12 \\
\hline NPAS3 & Neuronal PAS domain protein 3 & -4.09 \\
\hline FLJ16734 & Uncharacterized LOC641928 & -4.06 \\
\hline LRRTM4 & Leucine rich repeat transmembrane neuronal 4 & -4.04 \\
\hline TPTE2 & Transmembrane phosphoinositide 3-phosphatase and tensin homolog 2 & -3.95 \\
\hline FLJ36777 & Uncharacterized LOC730971 & -3.91 \\
\hline DNAII & Dynein, axonemal, intermediate chain 1 & -3.88 \\
\hline $\mathrm{ROBO4}$ & Roundabout, axon guidance receptor, homolog 4 (Drosophila) & -3.84 \\
\hline$A L O X 15$ & Arachidonate 15-lipoxygenase & -3.79 \\
\hline OLIG3 & Oligodendrocyte transcription factor 3 & -3.78 \\
\hline MON2 & MON2 homolog (S. cerevisiae) & -3.76 \\
\hline MON2 & MON2 homolog (S. cerevisiae) & -3.75 \\
\hline CASC11 & Cancer susceptibility candidate 11 (non-protein coding) & -3.68 \\
\hline CRISP2 & Cysteine-rich secretory protein 2 & -3.68 \\
\hline$R A B 41$ & RAB41, member RAS oncogene family & -3.61 \\
\hline ALS2CR12 & Amyotrophic lateral sclerosis 2 (juvenile) chromosome region, candidate 12 & -3.56 \\
\hline GLYCTK & Glycerate kinase & -3.55 \\
\hline NCRNA00250 & Non-protein coding RNA 250 & -3.51 \\
\hline$V C A M 1$ & Vascular cell adhesion molecule 1 & -3.44 \\
\hline OPALIN & Oligodendrocytic myelin paranodal and inner loop protein & -3.41 \\
\hline$A K N A D 1$ & AKNA domain containing 1 & -3.40 \\
\hline
\end{tabular}


Table V. Continued.

\begin{tabular}{llc}
\hline Gene symbol & \multicolumn{1}{c}{ Gene name } & Fold-change \\
\hline ATP1A2 & ATPase, $\mathrm{Na}^{+} / \mathrm{K}^{+}$transporting, , 2 polypeptide & -3.39 \\
OTOGL & Otogelin-like & -3.35 \\
MUC6 & Mucin 6, oligomeric mucus/gel-forming & -3.33 \\
FAM230A & Family with sequence similarity 230, member A & -3.32 \\
KRT6A & Keratin 6A, type II & -3.32 \\
SLC25A21-AS1 & SLC25A21 antisense RNA 1 & -3.31 \\
GLYCTK & Glycerate kinase & -3.29 \\
DRD2 & Dopamine receptor D2 & -3.29 \\
CECR6 & Cat eye syndrome chromosome region, candidate 6 & -3.29 \\
PRKCQ-AS1 & PRKCQ antisense RNA 1 & -3.28 \\
ADAMTS6 & ADAM metallopeptidase with thrombospondin type 1 motif, 6 \\
CCDC178 & Coiled-coil domain containing 178 & -3.27 \\
LTN1 & Listerin E3 ubiquitin protein ligase 1 & -3.26 \\
C10orf71-AS1 & C10orf71 antisense RNA 1 & -3.25 \\
SPDYE5 & Speedy/RINGO cell cycle regulator family member E5 & -3.23 \\
CD180 & CD180 molecule & -3.21 \\
DPY19L2 & Dpy-19-like 2 (C. elegans) & -3.20 \\
SCEL & Sciellin & -3.20 \\
PTGIR & Prostaglandin I2 (prostacyclin) receptor (IP) & -3.13 \\
ABCB1 & ATP-binding cassette, sub-family B (MDR/TAP), member 1 \\
ABCC2 & ATP-binding cassette, sub-family C (CFTR/MRP), member 2 & -3.10 \\
MYL10 & Myosin, light chain 10, regulatory & -3.10 \\
OR5M9 & Olfactory receptor, family 5, subfamily M, member 9 & -3.09 \\
APCDD1L-AS1 & APCDD1L antisense RNA 1 (head to head) & -3.07 \\
SULT1B1 & Sulfotransferase family, cytosolic, 1B, member 1 & -3.06 \\
CFAP58 & Cilia and flagella-associated protein 58 & -3.06 \\
TERF1 & Telomeric repeat binding factor (NIMA-interacting) 1 & -3.05 \\
\hline & & -3.03 \\
& & -3.03 \\
\hline
\end{tabular}

Table VI. Functional gene annotation clustering analysis of annotation cluster one (enrichment score: 3.12) based on the Database for Annotation, Visualization and Integrated Discovery algorithm ${ }^{\mathrm{a}}$.

\begin{tabular}{llcc}
\hline & \multicolumn{3}{c}{ No.of } \\
Category & \multicolumn{1}{c}{ Term } & genes & P-value \\
\hline UP_KEYWORDS & Glycoprotein & 66 & $8.32 \times 10^{-5}$ \\
UP_SEQ_FEATURE & Signal peptide & 51 & $1.21 \times 10^{-4}$ \\
UP_SEQ_FEATURE & Glycosylation & 58 & $5.77 \times 10^{-4}$ \\
& site:N-linked & & \\
& (GlcNAc...) & & \\
UP_KEYWORDS & Secreted & 33 & $1.09 \times 10^{-3}$ \\
UP_KEYWORDS & Signal & 57 & $1.45 \times 10^{-3}$ \\
UP_KEYWORDS & Disulfide bond & 49 & $1.64 \times 10^{-3}$ \\
& & &
\end{tabular}

apartial list of a functional annotation cluster was obtained by loading 216 genes, the expression of which included an increase or decrease of $>3$-fold following knockdown of leucine-rich repeat-containing 26 in HCC70 cells using a DNA microarray analysis.

\section{Acknowledgements}

The authors would like to thank Dr Junichi Kurebayashi (Kawasaki Medical School, Kurashiki, Okayama, Japan) for gifting the KPL-3C breast cancer cell line, and Ms. Hinako Koseki and Ms. Hitomi Kawakami (Division of Genome Medicine, Institute for Genome Research, Tokushima University, Tokushima, Japan) for providing excellent technical support.

\section{Funding}

This research was supported by the Tailor-Made Medical Treatment with the BBJ Project (grant no. 13418656) and Practical Research for Innovative Cancer Control (grant no. 12103129) from the Japan Agency for Medical Research and Development.

\section{Availability of data and materials}

The assessed TCGA data set was from the TCGA portal (http://cancergenome.nih.gov/). The RNA-Seq data (accession no. JGAS00000000116) used in Fig. 1A were deposit 
in the DNA DataBank of Japan (http://www.ddbj.nig.ac.jp/). The microarray data (GSE90582) were submitted to the NCBI Gene Expression Omnibus archive (https://www.ncbi. nlm.nih.gov/geo/).

\section{Authors' contributions}

YMiyagawa performed all experiments, interpreted all data and prepared the draft of the manuscript. YMatsushita performed the analyses for $L R R C 26$ expression, invasion, migration assay by Incucyte and immunocytochemical staining, interpreted all data and prepared the draft and final version of the manuscript. HS performed the methylation of LRRC26 and analyses for TCGA data sets. MK and TY provided the interpretation of LRRC26 expression and function. RK performed the analyses for the luciferase assay. AY and AT provided the interpretation of the clinical association data. JH and MS prepared the clinical specimens and provided the interpretation of the clinical association data. YMiyoshi discussed the interpretation of all data. TK was involved in the conception and design of all studies, the interpretation of the data, and the preparation of the draft and final version of the manuscript. All authors read and approved the final manuscript.

\section{Ethics approval and consent to participate}

The present study, as well as the use of all clinical materials aforementioned, was approved by the Ethics Committee of Tokushima University (permission no. H29-15 for expression profile analysis and permission no. H29-14 for RNA-seq analysis).

\section{Consent for publication}

Clinical specimens were obtained with informed consent from patients who were treated at the Tokushima Breast Care Clinic (Tokushima, Japan), as previously described (20), with permission to publish their data.

\section{Competing interests}

The authors declare that they have no competing interests.

\section{References}

1. Fisher B, Anderson S, Tan-Chiu E, Wolmark N, Wickerham DL, Fisher ER, Dimitrov NV, Atkins JN, Abramson N, Merajver S, et al: Tamoxifen and chemotherapy for axillary node-negative, estrogen receptor-negative breast cancer: Findings from National Surgical Adjuvant Breast and Bowel Project B-23. J Clin Oncol 19: 931-942, 2001.

2. Colleoni M, Gelber S, Goldhirsch A, Aebi S, CastiglioneGertsch M, Price KN, Coates AS and Gelber RD; International Breast Cancer Study Group: Tamoxifen after adjuvant chemotherapy for premenopausal women with lymph node-positive breast cancer: International Breast Cancer Study Group Trial 13-93. J Clin Oncol 24: 1332-1341, 2006.

3. Merglen A, Verkooijen HM, Fioretta G, Neyroud-Caspar I, Vinh-Hung V, Vlastos G, Chappuis PO, Castiglione M, Rapiti E and Bouchardy C: Hormonal therapy for oestrogen receptornegative breast cancer is associated with higher disease-specific mortality. Ann Oncol 20: 857-861, 2009.

4. Huszno J and Nowara E: Current therapeutic strategies of anti-HER 2 treatment in advanced breast cancer patients. Contemp Oncol (Pozn) 20: 1-7, 2016.
5. Foulkes WD, Smith IE and Reis-Filho JS: Triple-negative breast cancer. N Engl J Med 363: 1938-1948, 2010.

6. Liedtke C, Mazouni C, Hess KR, André F, Tordai A, Mejia JA, Symmans WF, Gonzalez-Angulo AM, Hennessy B, Green M, et al: Response to neoadjuvant therapy and long-term survival in patients with triple-negative breast cancer. J Clin Oncol 26 : $1275-1281,2008$

7. Gradishar WJ, Anderson BO, Balassanian R, Blair SL, Burstein HJ, Cyr A, Elias AD, Farrar WB, Forero A, Giordano SH, et al: Invasive Breast Cancer Version 1.2016, NCCN Clinical Practice Guidelines in Oncology. J Natl Compr Canc Netw 14: 324-354, 2016.

8. Cortes J, O'Shaughnessy J, Loesch D, Blum JL, Vahdat LT, Petrakova K, Chollet P, Manikas A, Diéras V, Delozier T, et al; EMBRACE (Eisai Metastatic Breast Cancer Study Assessing Physician's Choice Versus E7389) investigators: Eribulin monotherapy versus treatment of physician's choice in patients with metastatic breast cancer (EMBRACE): A phase 3 open-label randomised study. Lancet 377: 914-923, 2011

9. Denkert C, Liedtke C, Tutt A and von Minckwitz G: Molecular alterations in triple-negative breast cancer-the road to new treatment strategies. Lancet 389: 2430-2442, 2017.

10. Kim JE, Ahn HJ, Ahn JH, Yoon DH, Kim SB, Jung KH, Gong GY, Kim MJ, Son BH and Ahn SH: Impact of triple-negative breast cancer phenotype on prognosis in patients with stage I breast cancer. J Breast Cancer 15: 197-202, 2012.

11. Lehmann BD, Bauer JA, Chen X, Sanders ME, Chakravarthy AB, Shyr Y and Pietenpol JA: Identification of human triple-negative breast cancer subtypes and preclinical models for selection of targeted therapies. J Clin Invest 121: 2750-2767, 2011.

12. Cancer Genome Atlas N; Cancer Genome Atlas Network: Comprehensive molecular portraits of human breast tumours. Nature 490: 61-70, 2012.

13. Pereira B, Chin SF, Rueda OM, Vollan HK, Provenzano E, Bardwell HA, Pugh M, Jones L, Russell R, Sammut SJ, et al: The somatic mutation profiles of 2,433 breast cancers refines their genomic and transcriptomic landscapes. Nat Commun 7: 11479, 2016.

14. Shah SP, Roth A, Goya R, Oloumi A, Ha G, Zhao Y, Turashvili G, Ding J, Tse K, Haffari G, et al: The clonal and mutational evolution spectrum of primary triple-negative breast cancers. Nature 486: 395-399, 2012.

15. O'Shaughnessy J, Osborne C, Pippen JE, Yoffe M, Patt D, Rocha C, Koo IC, Sherman BM and Bradley C: Iniparib plus chemotherapy in metastatic triple-negative breast cancer. $\mathrm{N}$ Engl J Med 364: 205-214, 2011.

16. Tutt A, Robson M, Garber JE, Domchek SM, Audeh MW, Weitzel JN, Friedlander M, Arun B, Loman N, Schmutzler RK, et al: Oral poly(ADP-ribose) polymerase inhibitor olaparib in patients with BRCA1 or BRCA2 mutations and advanced breast cancer: A proof-of-concept trial. Lancet 376: 235-244, 2010.

17. Yamaguchi N, Ito T, Azuma S, Ito E, Honma R, Yanagisawa $Y$, Nishikawa A, Kawamura M, Imai J, Watanabe S, et al: Constitutive activation of nuclear factor-kappaB is preferentially involved in the proliferation of basal-like subtype breast cancer cell lines. Cancer Sci 100: 1668-1674, 2009.

18. Liu XF, Xiang L, Zhang Y, Becker KG, Bera TK and Pastan I: CAPC negatively regulates NF- $\kappa \mathrm{B}$ activation and suppresses tumor growth and metastasis. Oncogene 31: 1673-1682, 2012.

19. Kurebayashi J, Kurosumi M and Sonoo H: A new human breast cancer cell line, KPL-3C, secretes parathyroid hormone-related protein and produces tumours associated with microcalcifications in nude mice. Br J Cancer 74: 200-207, 1996.

20. Komatsu M, Yoshimaru T, Matsuo T, Kiyotani K, Miyoshi Y, Tanahashi T, Rokutan K, Yamaguchi R, Saito A, Imoto S, et al: Molecular features of triple negative breast cancer cells by genome-wide gene expression profiling analysis. Int J Oncol 42: 478-506, 2013.

21. Livak KJ and Schmittgen TD: Analysis of relative gene expression data using real-time quantitative PCR and the 2(-Delta Delta C(T)) method. Methods 25: 402-408, 2001.

22. Kim JW, Akiyama M, Park JH, Lin ML, Shimo A, Ueki T, Daigo Y, Tsunoda T, Nishidate T, Nakamura Y, et al: Activation of an estrogen/estrogen receptor signaling by BIG3 through its inhibitory effect on nuclear transport of PHB2/REA in breast cancer. Cancer Sci 100: 1468-1478, 2009.

23. Park JH, Lin ML, Nishidate T, Nakamura $Y$ and Katagiri T: PDZ-binding kinase/T-LAK cell-originated protein kinase, a putative cancer/testis antigen with an oncogenic activity in breast cancer. Cancer Res 66: 9186-9195, 2006. 
24. Kamimae S, Yamamoto E, Kai M, Niinuma T, Yamano HO, Nojima M, Yoshikawa K, Kimura T, Takagi R, Harada E, et al: Epigenetic silencing of NTSR1 is associated with lateral and noninvasive growth of colorectal tumors. Oncotarget 6 : 29975-29990, 2015.

25. Ng FW, Nguyen M, Kwan T, Branton PE, Nicholson DW, Cromlish JA and Shore GC: p28 Bap31, a Bcl-2/Bcl-XL- and procaspase-8-associated protein in the endoplasmic reticulum. J Cell Biol 139: 327-338, 1997.

26. Annaert WG, Becker B, Kistner U, Reth M and Jahn R: Export of cellubrevin from the endoplasmic reticulum is controlled by BAP31. J Cell Biol 139: 1397-1410, 1997.

27. Huang W, Sherman BT and Lempicki RA: Systematic and integrative analysis of large gene lists using DAVID bioinformatics resources. Nat Protoc 4: 44-57, 2009.

28. Huang W, Sherman BT and Lempicki RA: Bioinformatics enrichment tools: Paths toward the comprehensive functional analysis of large gene lists. Nucleic Acids Res 37: 1-13, 2009.

29. Hao JM, Chen JZ, Sui HM, Si-Ma XQ, Li GQ, Liu C, Li JL, Ding YQ and Li JM: A five-gene signature as a potential predictor of metastasis and survival in colorectal cancer. J Pathol 220: 475-489, 2010

30. Yoshimaru T, Komatsu M, Matsuo T, Chen YA, Murakami Y, Mizuguchi K, Mizohata E, Inoue T, Akiyama M, Yamaguchi R, et al: Targeting BIG3-PHB2 interaction to overcome tamoxifen resistance in breast cancer cells. Nat Commun 4: 2443, 2013.

31. Kajiura K, Masuda K, Naruto T, Kohmoto T, Watabnabe M, Tsuboi M, Takizawa H, Kondo K, Tangoku A and Imoto I: Frequent silencing of the candidate tumor suppressor TRIM58 by promoter methylation in early-stage lung adenocarcinoma. Oncotarget 8: 2890-2905, 2017.

32. Locke WJ and Clark SJ: Epigenome remodelling in breast cancer: Insights from an early in vitro model of carcinogenesis. Breast Cancer Res 14: 215, 2012.

33. Wang X: miRDB: A microRNA target prediction and functional annotation database with a wiki interface. RNA 14: 1012-1017, 2008.
34. Peña-Chilet M, Martínez MT, Pérez-Fidalgo JA, Peiró-Chova L, Oltra SS, Tormo E, Alonso-Yuste E, Martinez-Delgado B, Eroles $\mathrm{P}$, Climent $\mathrm{J}$, et al: MicroRNA profile in very young women with breast cancer. BMC Cancer 14: 529, 2014.

35. Nguyen HT, Li C, Lin Z, Zhuang Y, Flemington EK, Burow ME, Lin YI and Shan B: The microRNA expression associated with morphogenesis of breast cancer cells in three-dimensional organotypic culture. Oncol Rep 28: 117-126, 2012.

36. Yan J and Aldrich RW: BK potassium channel modulation by leucine-rich repeat-containing proteins. Proc Natl Acad Sci USA 109: 7917-7922, 2012.

37. Carvalho S, Oliveira T, Bartels MF, Miyoshi E, Pierce M, Taniguchi N, Carneiro F, Seruca R, Reis CA, Strahl S, et al: $\mathrm{O}$-mannosylation and $\mathrm{N}$-glycosylation: Two coordinated mechanisms regulating the tumour suppressor functions of E-cadherin in cancer. Oncotarget 7: 65231-65246, 2016.

38. Couldrey C and Green JE: Metastases: The glycan connection. Breast Cancer Res 2: 321-323, 2000.

39. Dall'Olio F, Malagolini N, Trinchera M and Chiricolo M: Mechanisms of cancer-associated glycosylation changes. Front Biosci (Landmark Ed) 17: 670-699, 2012.

40. Pinho SS and Reis CA: Glycosylation in cancer: Mechanisms and clinical implications. Nat Rev Cancer 15: 540-555, 2015.

41. Wolff AC, Hammond ME, Hicks DG, Dowsett M, McShane LM, Allison KH, Allred DC, Bartlett JM, Bilous M, Fitzgibbons P, et al; American Society of Clinical Oncology; College of American Pathologists: Recommendations for human epidermal growth factor receptor 2 testing in breast cancer: American Society of Clinical Oncology/College of American Pathologists clinical practice guideline update. J Clin Oncol 31: 3997-4013, 2013.

42. Sobin L, Gospodarowicz M and Wittekind C (eds): TNM Classification of Malignant Tumors. John Wiley \& Sons, Inc., Hoboken, NJ, 2010. 